\title{
A new metriorhynchid crocodylomorph from the Oxford Clay Formation (Middle Jurassic) of England, with implications for the origin and diversification of Geosaurini
}

\author{
Davide Foffa ${ }^{\mathrm{a} *}$, Mark T. Young ${ }^{\mathrm{a}}$, Stephen L. Brusatte ${ }^{\mathrm{a}, \mathrm{b}}$, Mark R. Graham $^{\mathrm{c}, \S}$ and Lorna Steel ${ }^{\mathrm{d}, \S}$ \\ ${ }^{a}$ School of Geosciences, University of Edinburgh, Grant Institute, James Hutton Road, Edinburgh, EH9 3FE, UK; ${ }^{b}$ National Museums \\ Scotland, Chambers Street, Edinburgh, EHI IJF, UK; ${ }^{c}$ Core Research Laboratories, Natural History Museum, Cromwell Road, London, \\ SW7 5BD, UK; ${ }^{d}$ Department of Earth Sciences, Natural History Museum, Cromwell Road, London, SW7 5BD, UK
}

(Received 3 April 2017; accepted 1 August 2017)

\begin{abstract}
Metriorhynchids are an extinct group of Jurassic-Cretaceous crocodylomorphs secondarily adapted to a marine lifestyle. A new metriorhynchid crocodylomorph from the Oxford Clay Formation (Callovian, Middle Jurassic) of England is described. The specimen is a large, fragmentary skull and associated single ramus of a lower jaw uniquely preserved in a septarian concretion. The description of the specimen reveals a series of autapomorphies (apicobasal flutings on the middle labial surface of the tooth crowns, greatly enlarged basoccipital tuberosities) and a unique combination of characters that warrant the creation of a new genus and species: Ieldraan melkshamensis gen. et sp. nov. This taxon shares numerous characters with the Late Jurassic-Early Cretaceous genus Geosaurus: tooth crowns that have three apicobasal facets on their labial surface, subtly ornamented skull and lower jaws elements, and reception pits along the lateral margin of the dentary (maxillary overbite). Phylogenetic analysis places this new species as the sister taxon to Geosaurus. The new taxon adds valuable information on the time of origin of the macrophagous subclade Geosaurini, which was initially thought to have evolved and radiated during the Late Jurassic. The presence of Ieldraan melkshamensis, the phylogenetic re-evaluation of Suchodus durobrivensis as a Plesiosuchus sister taxon and recently identified Callovian Dakosaurus-like specimens in the Oxford Clay Formation, indicate that all major Geosaurini lineages originated earlier than previously supposed. This has major implications for the evolution of macropredation in the group. Specifically, we can now demonstrate that the four different forms of true ziphodonty observed in derived geosaurins independently evolved from a single non-functional microziphodont common ancestor.
\end{abstract}

http://zoobank.org/urn:lsid:zoobank.org:pub:7A400670-A339-463F-8CD4-8704745CB312

Keywords: Ieldraan; Melksham monster; Geosaurus; Geosaurini; Jurassic; macrophagy

\section{Introduction}

Metriorhynchids are an extinct clade of pelagic crocodylomorphs that were geographically widespread at low latitudes during the Jurassic and Cretaceous (EudesDeslongchamps 1867-1869; Fraas 1902; Andrews 1913; Pol \& Gasparini 2009; Young et al. 2010; Fernández et al. 2011; Herrera et al. 2015; Chiarenza et al. 2015; Mannion et al. 2015; Wilberg 2015; Barrientos-Lara et al. 2016). Recent studies have revealed disparate craniomandibular and dental morphologies among these species, which supported a wide spectrum of feeding behaviours, and thus diets (Andrade et al. 2010; Young et al. 2010, 2011a, 2012a). The typical piscivorous forms are phylogenetically grouped in Metriorhynchinae, whilst the other subfamily, Geosaurinae, evolved clear macropredatory features in the most derived forms, Geosaurini (sensu Cau \& Fanti 2011) (Pol \& Gasparini 2009; Andrade et al. 2010; Young et al. 2011a, b, 2012b).

Recent revisions of the taxonomy of Oxford Clay Formation (OCF) metriorhynchids suggest that the evolution of macropredatory adaptations within Geosaurinae may be more complex than previously thought, and these features may have developed particularly early in metriorhynchid evolution (Young et al. 2013a). In particular, craniomandibular and dental morphologies described in Tyrannoneustes lythrodectikos, Dakosaurus-like specimens (the 'Mr Leeds' Dakosaur' OTU in the phylogenetic analysis of Young et al. 2016) from England and northern France, and the phylogenetic reassessment of Suchodus durobrivensis, showed that major macrophagous adaptations had already evolved by the late Middle Jurassic

\footnotetext{
*Corresponding author. Email: D.Foffa@sms.ed.ac.uk

${ }^{\S}$ Authors listed in alphabetical order. 
(Lepage et al. 2008; Young et al. 2013a, 2016; Foffa \& Young 2014). The only major exception appears to be the unique occluding mechanism of the Late JurassicCretaceous genus Geosaurus (Young \& Andrade 2009; Andrade et al. 2010), which seems to have been a later development.

Within this context, we describe a new genus of OCF metriorhynchid based on a large individual, NHMUK PV OR 46797. The new taxon shows striking morphological similarities with the genus Geosaurus. However, the differences are enough to establish a new taxon, Ieldraan melkshamensis gen. et sp. nov., based on autapomorphies and a unique combination of characters. Our phylogenetic analysis supports Ieldraan melkshamensis as the sister taxon to Geosaurus. The presence of Ieldraan melkshamensis in the OCF pushes the origins of the Geosaurus subclade (here formally defined as Geosaurina subtr. nov.) back to, at least, the late Middle Jurassic. The unique dental morphology of this new taxon demonstrates that the evolution of ziphodonty in Geosaurini is more complex than previously hypothesized, as it seems to have evolved independently three or four times in Metriorhynchidae. Finally, the occurrence of a geosaurin-like taxon in the OCF demonstrates that all major Geosaurini clades were already present (even though their occurrence was much rarer) before achieving the large diversity recorded in Late Jurassic European formations.

\section{Material and methods}

\section{Material}

Specimen NHMUK PV OR 46797 was purchased in 1875 by the British Museum (Natural History), and it now resides in the NHMUK, as part of the Cunnington Collection. The specimen has only been mentioned once in the literature, by Lydekker (1888, p. 97), who described it as: "Mass of matrix containing portions of the cranium and mandible; from the Oxford Clay of Melksham, Wiltshire. The occipital condyle, part of the premaxilla with teeth, as well as a large portion of the left ramus of the mandible with teeth are well preserved; the enamel of the teeth is fluted.", and referred it to Metriorhynchus moreli (a subjective junior synonym of Metriorhynchus superciliosus). In 2013, one of us (MRG) undertook painstaking mechanical preparation that exposed new details of the skull, lower jaw and teeth that were previously hidden within the matrix. The specimen is extensively damaged and crossed by several veins of calcite. The radial pattern of the veins is typical of septarian nodules, a particular kind of concretion (Sellés-Martínez 1996; Hendry et al. 2006). These nodules are the result of physical and chemical processes (perhaps caused by bacterial activity) during marine mudrock diagenesis (Hendry et al. 2006), specifically the expansion of boulders caused by the circulation of inner fluids, the deposition of minerals, or by the contraction of boulders caused by chemical extraction of fluids (Sellés-Martínez 1996; Hendry et al. 2006). Regardless of the mode of septarian formation, the diagenetic processes caused major physical damage to the dorsal and lateral sides of the skull.

Institutional abbreviations

BRSMG: Bristol Museum \& Art Gallery, Bristol, UK; BSPG: Bayerische Staatssammlung für Paläontologie und Geologie, Munich, Germany; CAMSM: Sedgwick Museum, Cambridge, UK; DORCM: Dorset County Museum, Dorchester, UK; GLAHM: Hunterian Museum, Glasgow, UK; NHMUK: Natural History Museum, London, UK; MJML: Museum of Jurassic Marine Life the Steve Etches Collection, Kimmeridge, Dorset, UK; MOZ: Museo Profesor J. Olsacher, Zapala, Argentina; MPV: Musée Paléontologique de Villers-sur-Mer, Calvados, France; MNHN: Muséum National d'Histoire Naturelle, Paris, France; OUMNH: Oxford University Museum of Natural History, Oxford, UK; PETMG: Peterborough Museum \& Art Gallery, Peterborough, UK; SMNS, Staatliches Museum für Naturkunde, Stuttgart, Germany.

\section{Anatomical abbreviations}

an: angular; boc: basioccipital; bt: basioccipital tuberosity; cp: coronoid process; D: dentary tooth or alveolus; den: dentary; exo: exoccipital; fm: foramen magnum; fr: frontal; j: jugal; lsph: laterosphenoid; M: maxillary tooth or alveolus; mc: meatal chamber; mx: maxilla; nas: nasal; nf: nutrient foramen; oc: occipital condyle; orb: orbit; $\mathbf{P}$ : premaxillary tooth or alveolus; par: parietal; pmx: premaxilla; po: post-orbital; pop: paroccipital process of the opisthotic; prf: possible prefrontal fragment; pro: prootic; qj: quatratojugal; qu: quadrate; rp: reception pit; san: surangular; san-den gr: surangulodentary groove; so: supraoccipital; spl: splenial; sq: squamosal; stf: supra-temporal fenestra; tc: tooth.

Abbreviations for teeth and alveoli are followed by numbers referring to their relative order, for example M1 would be the anteriormost maxillary tooth or alveolus.

\section{Systematic palaeontology}

Superorder Crocodylomorpha Hay, 1930 (sensu Walker 1970)

Suborder Thalattosuchia Fraas, 1901 (sensu Young \& Andrade 2009)

Family Metriorhynchidae Fitzinger, 1843 (sensu Young \& Andrade 2009)

Subfamily Geosaurinae Lydekker, 1889 (sensu Young \& Andrade 2009) 
Tribe Geosaurini Lydekker, 1889 (sensu Cau \& Fanti 2011)

Subtribe Geosaurina subtr. nov.

Type genus. Geosaurus Cuvier, 1824 (sensu Young et al. 2012a).

Geological range. Middle Callovian to Valanginian ( $\sim 34$ myr duration).

Geographical range. European endemic (UK, Germany and France).

Diagnosis. Metriorhynchid crocodylomorphs with the following unique combination of characters (autapomorphic characters are indicated by an asterisk ${ }^{*}$ ): inconspicuously ornamented maxillae; teeth with three apicobasal facets on the labial surfaces*; laminar (strongly mediolaterally compressed) teeth dominate the dentition*; maxillary tooth row overbites the dentary tooth row*.

\section{Genus Ieldraan gen. nov.}

Type species. Ieldraan melkshamensis gen. et sp. nov.

Diagnosis. Same as for the only known species (monogeneric).

Derivation of the name. 'Older One'. Ieldra, Old English for older; and an, Old English for one, referring to the stratigraphically older age of this new genus compared to its close relative Geosaurus.

\section{Ieldraan melkshamensis sp. nov.} (Figs 1-4)

1888 Metriorhynchus moreli Eudes-Deslongchamps; Lydekker: 97.

Holotype. NHMUK PV OR 46797, an incomplete and severely diagenetically damaged skull (including fragments of maxilla, portions of the nasals, frontal, both prefrontals, postorbitals, left squamosal, basioccipital, occipital condyle, exoccipital-opisthotic and quadratojugal) and left mandibular ramus (incomplete dentary, splenial, angular and surangular). The skull is dorsolaterally flattened with several disarticulated skull roof and rostral elements. The left mandible is preserved and exposed in lateral view. The right mandible is either lost or still embedded in the matrix. Several teeth, some of which are complete, are preserved in life-position on both skull and lower jaw.

Diagnosis. Metriorhynchid crocodylomorph with the following unique combination of characters (autapomorphic characters are indicated by an asterisk ${ }^{*}$ ): apicobasal parallel flutings on the middle facet of the labial surface*; enlarged tooth crowns; denticulated keeled carinae with microscopic, poorly developed, non-contiguous, non- uniform in size and shape denticles; ornamentation of skull and mandible elements consisting of small pits and enlarged basioccipital tuberosities*.

Additionally, the hypoglossal nerve opening is situated below the level of the ventral rim of the foramen magnum*. This could also be a diagnostic feature, but without CT scans from a well-preserved specimen it is difficult to be sure of the correct location of the hypoglossal nerve opening (see Description).

Derivation of name. 'Older One from Melksham', epithet translated from Latin, locative case.

\section{Description.}

Cranium. NHMUK PV OR 46797 is an incomplete and severely damaged skull and associated left mandibular ramus. The skull is flattened and exposed in dorsal/left lateral view, was diagenetically broken into several fragments and is locally reduced to shards (Figs 1-3). The left mandible is also exposed in lateral view, and misses the anterior dentary and the articular area. The maxillae, frontal, both prefrontals, large parts of both postorbitals, the left squamosal, the parietal and various broken bones on the occipital complex can be confidently identified. The premaxilla and the anterior part of the nasals have been lost during diagenesis, unlike the orbital area, which is recognizable in dorsal view (Figs 1, 3). Similarly, the deformed boundary of the left supratemporal area can be followed in dorsal view (Figs 1, 3G, K). Close examination of the specimen revealed that the intertemporal bar must have collapsed on its right side. Subsequent diagenesis obliterated most of this area, leaving only the posterior medial side of the left supratemporal fenestra intact (Fig. 3C). The occipital surface (Figs 2, 3E) emerges from one side of the block, where the paroccipital process of the opisthotic, the occipital condyle, the basioccipital tuberosities and parts of the quadrates are accessible. Approximately 10 teeth are preserved, but only three or four are complete enough to be described. They are still in life position in the left maxilla and dentary.

Numerous other fragments have been exposed during mechanical preparation. They include the posterior part of both nasals and the left jugal (and perhaps quadratojugal), and can be identified by their anatomical association with other elements (Figs 1,3). The rest of the skull - including premaxillae, the left-ventral side of the rostrum, the orbital and post-orbital areas, the braincase, most of the parietal-squamosal, the quadrates and the entire palate surface - are inaccessible, too fragmented or too crushed to be described.

Despite the fragmentary preservation, the external bone texture of all the major fragments is well preserved. Shallow grooves and small, densely packed pits ornament the surface of the largest skull and mandible fragments (Figs 1, $3 \mathrm{~A}, \mathrm{~B}, \mathrm{D})$. This same pattern is consistently found on the shallow fine grooves (shared with Geosaurus); greatly 

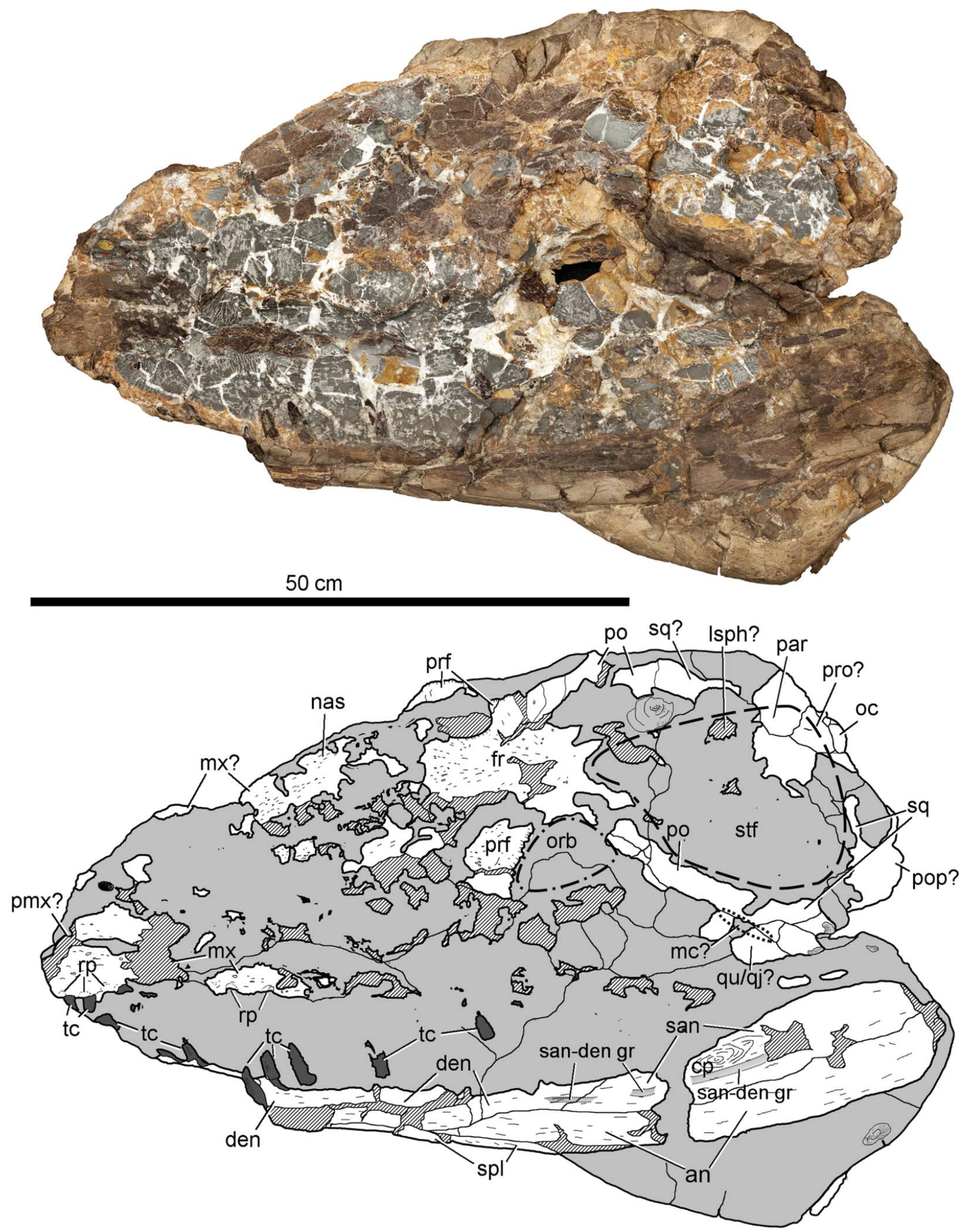

Figure 1. Skull and left mandibular ramus of Ieldraan melkshamensis gen. et sp. nov. (NHMUK PV OR 46797), and line interpretation in dorsolateral view. See text for abbreviations. The dashed line represents the approximate boundary of the left supratemporal fenestra; the dot-dashed line indicates the approximate position of the left orbit; the dotted line indicates the approximate position of the left meatal chamber; the cross-hatched pattern indicates damaged surfaces of the bone. 
external surface of the maxilla, frontal, ?nasals, dentary, angular, surangular and splenial. It is remarkably similar to the pattern described in Geosaurus species (Young \& Andrade 2009; Young et al. 2013a). In contrast, it radically differs from the dermatocranium ornamentation of any other metriorhynchids, especially the Callovian species. Metriorhynchid skulls are either conspicuously and heavily ornamented, as in Metriorhynchus superciliosus, Maledictosuchus riclaensis, 'Metriorhynchus' brachyrhynchus (NHMUK PV R 2168; NHMUK PV R 3699; NHMUK PV R 3700; NHMUK PV R 3804), Tyrannoneustes lythrodectikos (NHMUK PV R 3939; PETMG R176), Suchodus durobrivensis (NHMUK PV R 2039), and the best-preserved Dakosaurus-like specimens (NHMUK PV R 3321), or almost entirely smooth, as in Cricosaurus lithographicus, Dakosaurus andiniensis (MOZ 6146P), Plesiosuchus manselii (NHMUK PV OR 40103), Torvoneustes carpenteri (BRSMG Cd7203) and T. coryphaeus (MJML K1863) (Andrews 1913; Pol \& Gasparini 2009; Young \& Andrade 2009; Young et al. 2012b, 2013a, table 1; Herrera et al. 2013; Parrilla-Bel et al. 2013; Foffa \& Young 2014). Several contacts and other superficial features were obliterated by the mechanisms which led to the formation of the septarian nodule.

Neither maxilla is entirely preserved. Two large pieces of the right maxilla are exposed in lateral view and are the best source of morphological information for this element (Figs 1, 3D). It is not clear if either premaxilla is even partially preserved (contra Lydekker 1889), and the contact between the two elements - if it is present - is obscured by the poor preservation of the specimen in the area. Anteriorly, the lateral surface of the left maxilla is sufficiently well preserved to show some distinctive features including reception pits for dentary teeth, nutrient foramina and distinctive bone ornamentation (Fig. 3D).

The above-mentioned reception pits are seen in other metriorhynchids and are thought to be linked with tooth interlocking in macrophagous taxa (Young \& Andrade 2009; Young et al. 2012a, b, 2013b; Foffa \& Young 2014). In Geosaurus giganteus (NHMUK PV OR 37020) the D4 tooth is greatly enlarged in respect to the adjacent teeth, and it is hosted in a long notch between the P3 and M1 alveoli (Young \& Andrade 2009). Unfortunately, neither the size of the D4 tooth nor the presence of an enlarged reception pit can be assessed with certainty in NHMUK PV OR 46797 due to the poor preservation, but should they be observed in future, more complete specimens, it would be a feature shared with Geosaurus giganteus (NHMUK PV OR 37020).

In metriorhynchids (and thalattosuchians in general) the nasals are broad, slightly curved elements with a triangular shape in dorsal view (Andrews 1913). In NHMUK PV OR 46797 they are recognizable by their association with the fragments of the right maxilla and anterior extent of both prefrontals (Figs 1, 3A, H, K). Their ornamentation does not differ substantially from the other skull elements. Unfortunately, they cannot be described further due to poor preservation (Figs 1, 3A), as this area is crossed by major calcite veins that have reduced the majority of the medial frontal anterior process, nasals and maxillae into shards.

The prefrontals are exposed in dorsal view and are laterally well developed, an apomorphy of Metriorhynchidae (Andrews 1913). They are preserved in association with the frontal and their posterolateral crenulated edge is also still visible, overhanging the anterior part of the orbits (Figs 1, 3A, B). The right prefrontal is preserved in three or four pieces and its original shape is nearly impossible to assess (Fig. 3A, B). The posterior end of the prefrontalfrontal-nasal suture is preserved and visible, and in our interpretation, the line along which the right prefrontal detached from the rest of the skull could be the medial margin of this very suture. The left prefrontal was only exposed recently by mechanical preparation. Similar to its right counterpart, the left prefrontal is also detached from the main body of the frontal, along what looks like their sutural contact. Compared to the right prefrontal, its lateral and posterior margins are better preserved and, despite a large crack crossing it, the typical teardrop-shape in dorsal view - another apomorphy of Metriorhynchidae (Young \& Andrade 2009; Young et al. 2016) - is still recognizable (Figs 1, 3A).

The prefrontal is longer than wide - a typical condition of most metriorhynchids - and its lateral side describes a continuous convex curve with an inflexion forming a nearly $70^{\circ}$ angle with the anteroposterior axis of the skull. The value of the latter angle varies in metriorhynchids and has diagnostic importance, being small in Dakosaurus (approximately $50^{\circ}$ ), larger in most other geosaurines (approximately $60-70^{\circ}$ ) and larger (up to $90^{\circ}$ ) in metriorhynchines (Wilkinson et al. 2008; Young et al. 2013b, 2016).

The ornamentation pattern is inconspicuous and very similar to Geosaurus species in being dominated by small ( $\sim 0.5-2 \mathrm{~mm}$ in diameter) and densely distributed ornamental pits and shallow grooves. The latter are deeper along the lateral and posterior margin of the prefrontal than elsewhere on the skull and lower jaws (Young et al. 2013a).

In metriorhynchids, the anterodorsal margin of the orbit is overhung by the laterally expanded prefrontal, while the dorsal margin is constituted by the orbital notch, which is the narrowest point of the frontal (interorbital distance) on the skull roof (Andrews 1913). The orbital notch is formed by the lateral margins of the prefrontalfrontal and the anterior part of the postorbital bar, and can be seen in NHMUK PV OR 46797 (Figs 1, 3A, B). This allows us to recognize the location of both orbits, but not to measure their dimensions accurately.

The frontal is easily recognized among the skull elements, even though it is severely damaged. It is a large, 


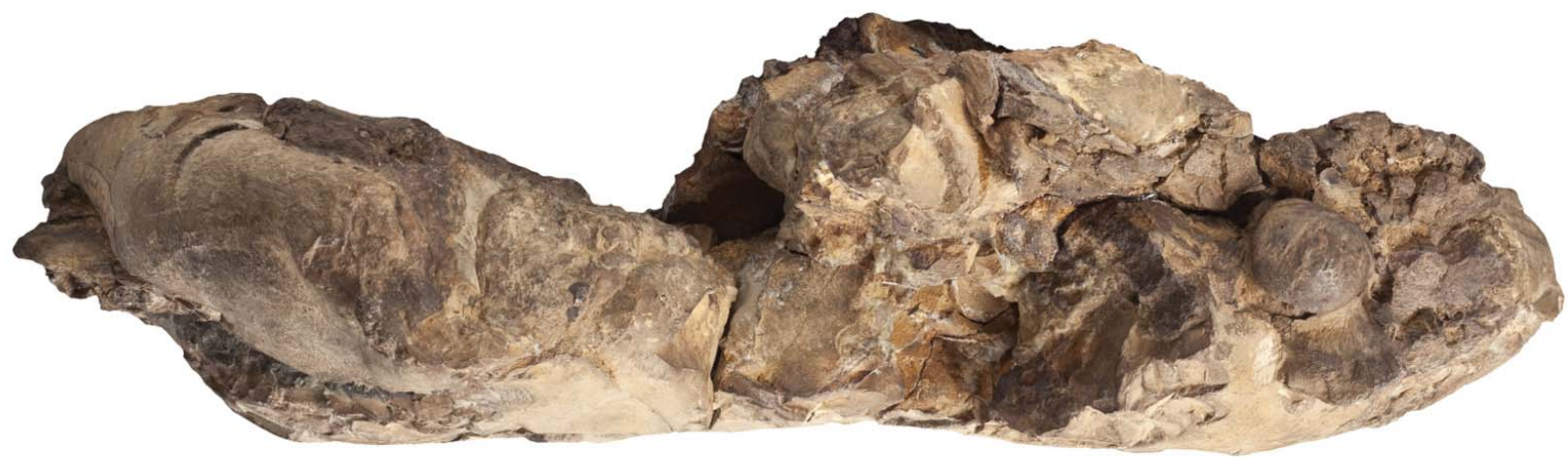

A
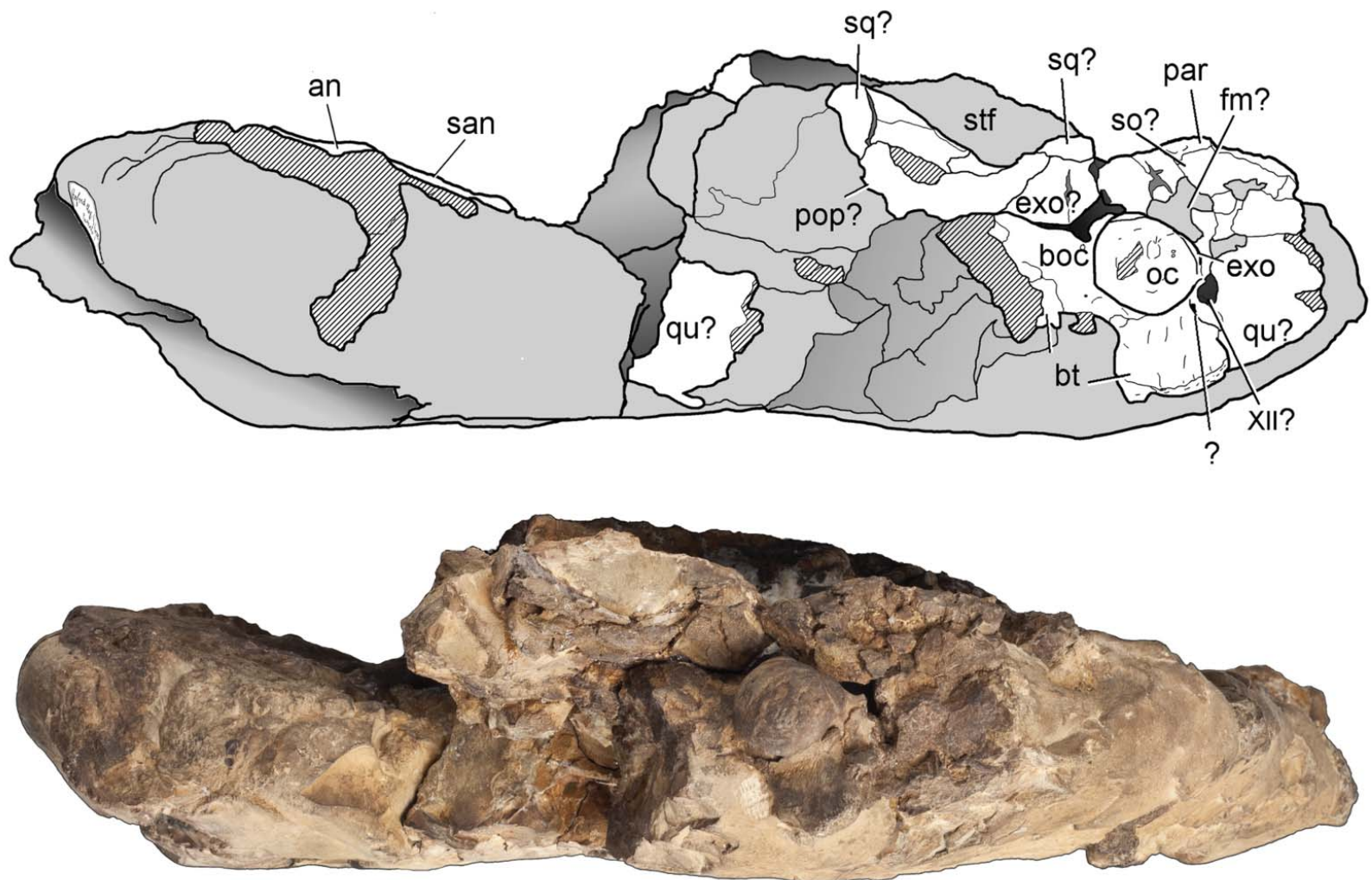

B

$30 \mathrm{~cm}$

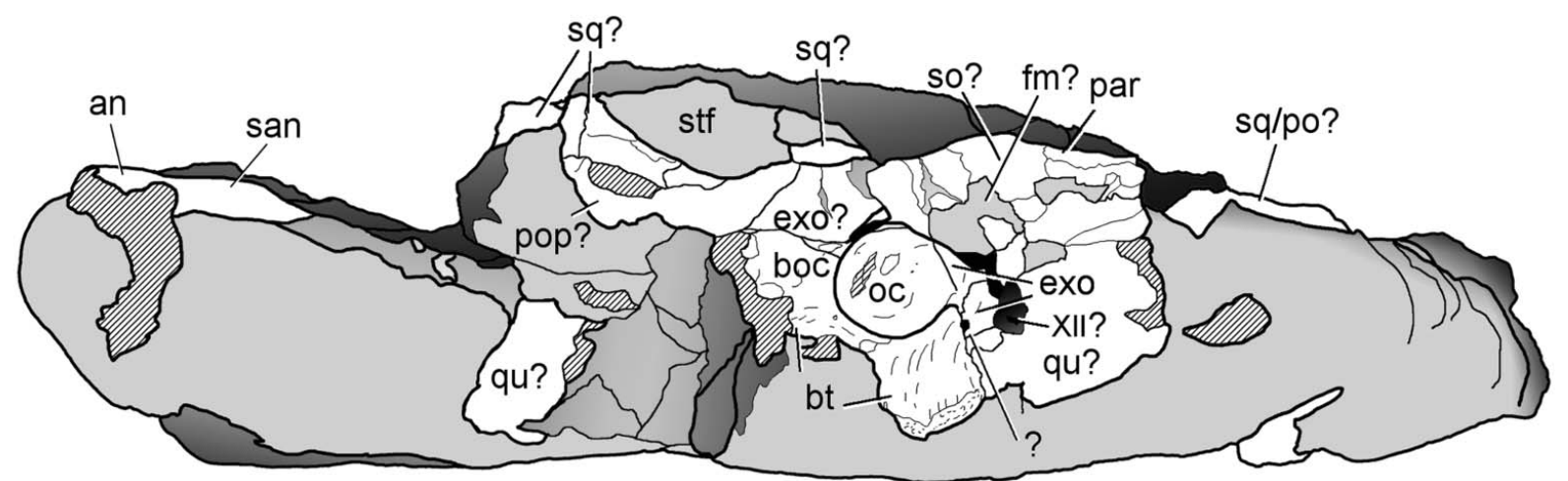

Figure 2. Skull and left mandibular ramus of Ieldraan melkshamensis gen. et sp. nov. (NHMUK PV OR 46797), and line interpretations. A, occipital view; B, oblique occipital view. See text for abbreviations. 
flat bone that extends from the posterior end of the snout to the middle margin of the supratemporal fossa, and it bears no sign of an interfrontal suture (Figs 1, 3A, H, K). All the processes of the frontal are damaged but preserved, with the exception of the anterior process that is completely destroyed along the anterior nasal-frontal suture (Figs 1, 3A). The medioposterior process is broken anterior to the frontal-parietal contact, while the left posterolateral process is still articulated with the postorbital (though the suture is unidentifiable) (Figs 1, 3A). In metriorhynchids the frontal participates in the dorsal margin of the orbit. This is visible on both sides but better preserved on the right side.

Posteriorly, the anteromedial margin of the left supratemporal fossa is intact. The angle between the lateral and medial posterior processes is $\sim 60-70^{\circ}$, within the range of geosaurines, with the exception of Dakosaurus andiniensis ( $\sim 45-50^{\circ}$, convergent with Cricosaurus) (Wilkinson et al. 2008; Pol \& Gasparini 2009; Cau \& Fanti 2011; Young et al. 2012b, 2013a; Cau 2013; Herrera et al. 2013; Foffa \& Young 2014), and narrower than in Metriorhynchus superciliosus, 'Metriorhynchus' casamiquelai, 'Metriorhynchus' westermanni and basal metriorhynchoids such as Pelagosaurus typus, Eoneustes species and Zoneait nagorum ( $\sim 90^{\circ}$ or obtuse angle) (Wilberg 2015).

The frontal ornamentation of Ieldraan melkshamensis is unique among Callovian geosaurines in being less conspicuous than other contemporaneous members of the subfamily (Fig. 3A) (Young \& Andrade 2009; Young et al. 2013b, table 1). The orientation of pits and grooves follows the typical radial pattern observed in all metriorhynchids (Fig. 1) (Andrews 1913; Young \& Andrade 2009; Young et al. 2013a, b). Interestingly, Gracilineustes leedsi is the only other metriorhynchid in the OCF that has a similarly smooth cranial ornamentation (NHMUK PV R3015, CAMSM J.64297, GLAHM V1009; PETMG R24; PETMG R72) (Andrews 1913). Ieldraan melkshamensis is the oldest Geosaurini with this type of dermal ornamentation pattern. This becomes very common in the Late Jurassic geosaurins Torvoneustes, Geosaurus and Dakosaurus, and replaces the heavily pitted and deeply grooved pattern of pre-Oxfordian metriorhynchids (Wilkinson et al. 2008; Pol \& Gasparini 2009; Young \& Andrade 2009; Young et al. 2012b, 2013b, table 1).

Posterior to the orbit, both postorbitals are preserved, although severely damaged (Figs 1, 3A, G). The right temporal bar is missing large sections posterior to the postorbital-squamosal contact (Figs 1-3). Conversely, the left upper temporal bar is well exposed in lateral view for most of its length (from the frontal to the upper and posterior borders of the meatal chamber) (Fig. 3G) (see Montefeltro et al. 2016 for an account of meatal chamber morphology in Thalattosuchia). The left squamosal and parts of the quadrate (and perhaps the quadratojugal) also sit in life position in dorsolateral view. The exact location of the postorbital-squamosal suture is not visible on either side. An additional section of the squamosal is visible in occipital view, sitting on top of the paroccipital process of the opisthotic (Figs 2, 3E).

The medial section of the supratemporal fossa is poorly preserved. As previously stated, the parietal-frontal contact is missing, as it is the largest part of the medial wall. This is normally composed by the frontal (anteriorly), parietal (posteriorly), and prootic and laterosphenoid (ventrally). In NHMUK PV OR 46797, this area is severely damaged by calcite veins, which made further preparation too precarious. However, some fragments emerge between the calcite veins and the matrix. These are the anteromedial corner of the left fenestra (see frontal section) (Fig. 3A), the left side of the medial processes of the parietal, the prootic, and the quadrate (and a partially covered fragment of the laterosphenoid) (Fig. 3C). The lateral exposure of the left parietal, ?prootic and potentially laterosphenoid suggests that the entire parietal bar has collapsed on its right side, an interpretation that is also supported by the rotation of the occipital complex. These elements constitute the posterior and medial corner of the left temporal fossa (Fig. 3C, K). We also report a medium-sized foramen ( $\sim-5 \mathrm{~mm}$ in diameter) piercing the parietal/prootics (arrow in Fig. 3C). This likely is a blood vessel foramen, such as the post-temporal canal (normally located between the parietal and prootic - and perhaps the quadrate if large; see Jouve 2009). In ' $M$.' cf. westermanni the post-temporal foramen is on the suture between the surapoccipital and partietal; however, this opening can be open or closed variably within a single species (e.g. Cricosaurus araucanensis) (Jouve 2009; Fernández et al. 2011). It is also possible that this foramen is a nerve opening for the temporo-orbital canal. Its position and shape are incompatible with the trigeminal (cranial nerve V) foramen, as this opening is usually larger in size, situated in a large fossa hosting the trigeminal ganglion, and pierces the prootic and laterosphenoid, as reported in ' $M$.' cf. westermanni (Fernández et al. 2011) and Steneosaurus cf. gracilirostris (NHMUK PV OR 33095) (Brusatte et al. 2016) (Fig. 3C). Poor preservation precludes access to these areas in NHMUK PV OR 46797.

Occipital surface. The entire occipital complex is compromised by breaks and has been tilted clockwise around the anteroposterior axis of the skull when seen in posterior view (Figs 1, 2, 3E). Similarly to the rest of the skull, only a few elements of the occipital complex are confidently identifiable, and many are partially or entirely missing (e.g. the quadrates). Unfortunately, the majority of bones are reduced into unidentifiable fragments and scattered in no clear anatomical connection. There are, however, some noticeable exceptions, amongst which are the basioccipital and exoccipital-opisthotics. 

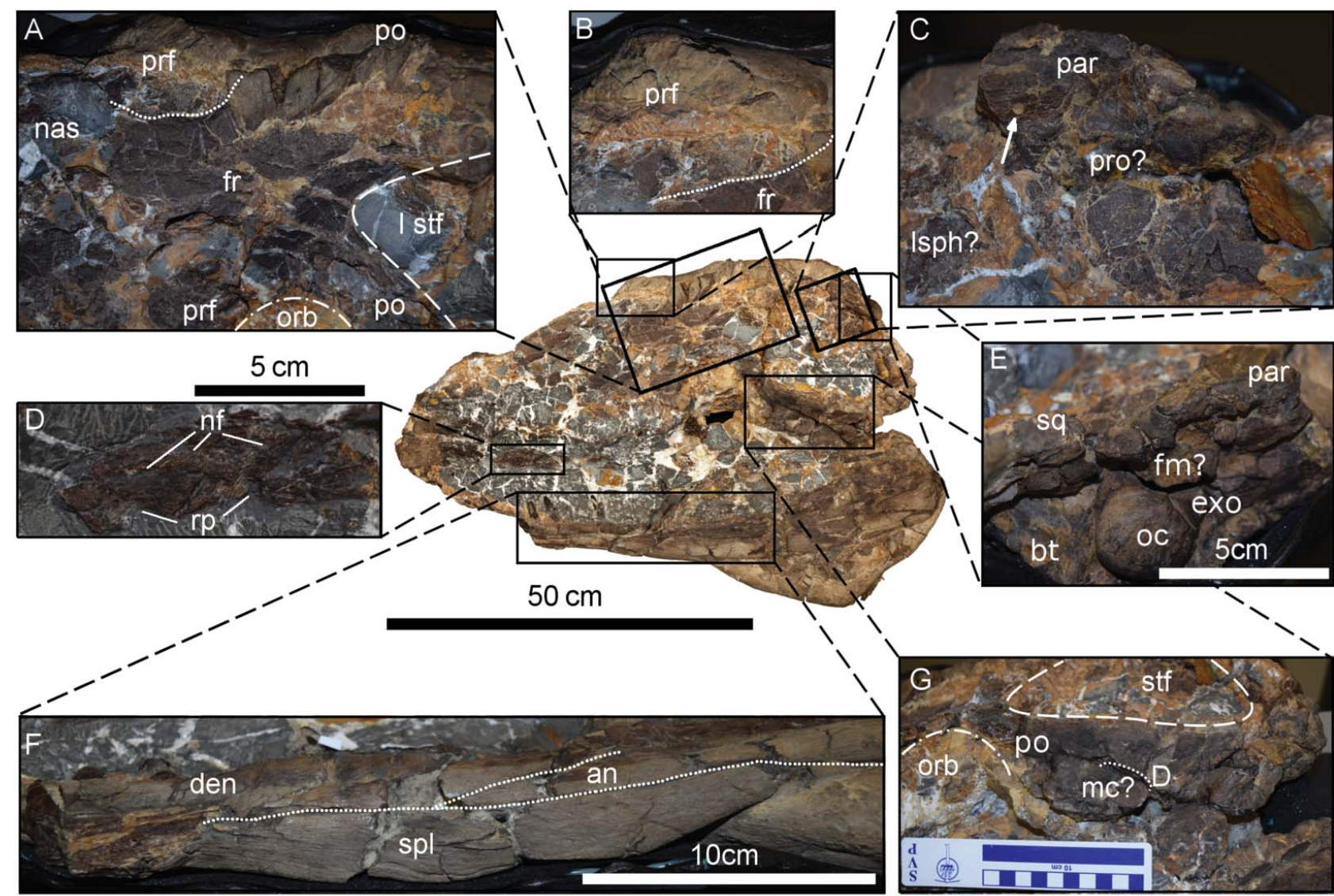

$\mathrm{H}$

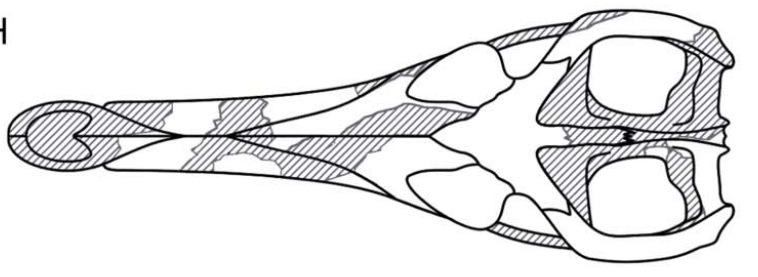

I

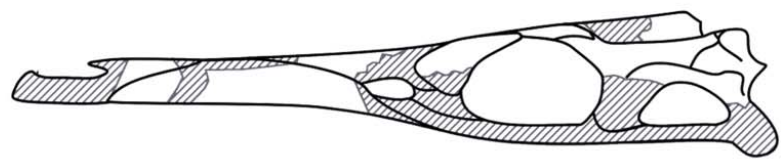

J
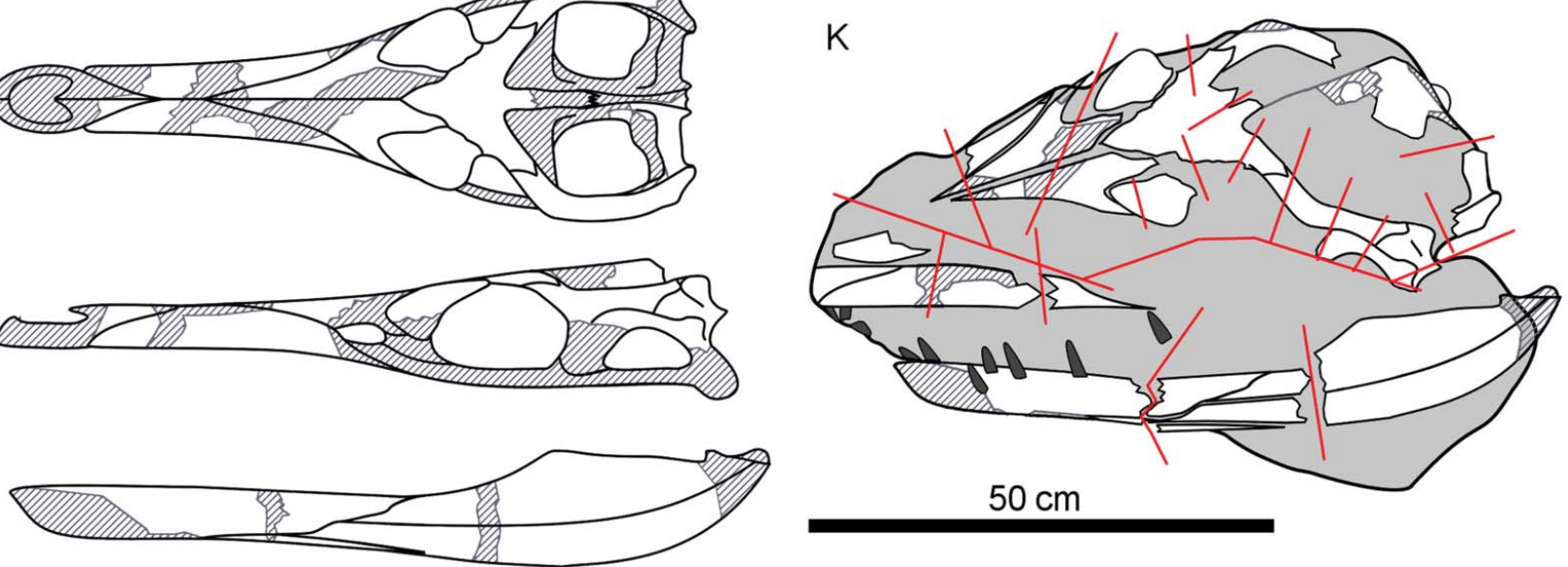

Figure 3. Details of the skull and left mandibular ramus of Ieldraan melkshamensis gen. et sp. nov. and line interpretation of a generic metriorhynchid skull showing the diagenetic preservation of the specimen. A, close-up of the frontal, prefrontal and postorbital area; B, close-up of the right prefrontal (the dotted line represents the prefrontal-frontal suture); $\mathbf{C}$, close-up of the posterior-medial corner of the left supratemporal fossa; $\mathbf{D}$, close-up of one fragment of the left maxilla (reception pits, nutritious foramina and bone ornamentations are visible); E, close-up of the occipital complex; F, left mandibular ramus in ventral view, showing the angular, splenial and dentary contacts and the end of the mandibular symphysis; $\mathbf{G}$, lateral view of the left postorbital bar (supratemporal fenestra, orbit and meatal chamber are highlighted); H, skull line interpretation in dorsal view; I, skull line interpretation in lateral view; J, mandible line interpretation in lateral view; K, simplified line interpretation of NHMUK PV OR 46797, showing the main skull elements and major line of fractures (red lines). The dashed line represents the approximate boundary of the left supratemporal fenestra; the dot-dashed line indicates the approximate position of the orbit; the arrow in $\mathbf{C}$ indicates a blood vessel/nerve foramen (see text for further discussion); the dashed grey areas in $\mathbf{H}-\mathbf{K}$ indicate heavily fragmented or missing areas. See text for abbreviations. 
The basioccipital is well preserved and forms the medial part of the occipital surface ventral to the foramen magnum (Figs 2, 3E). The most striking feature of its main constituents - the occipital condyle and basioccipital tuberosities (= basal tubera) - is their large size. The entire complex appears large compared to that of most other thalattosuchians, although the exact extent of this is difficult to quantify. In particular, the basioccipital tuberosities are unusually large in NHMUK PV OR 46797. Their posterior surface is mostly smooth, unlike the very rough ventral convexities. The two processes are separated by a wide Vshaped concavity in posterior view. The right tuberosity is better preserved and demonstrates that this structure is larger in Ieldraan melkshamensis than in any other metriorhynchid, and most resembles in size the basioccipital tuberosities of Machimosaurus spp. and 'Steneosaurus' herberti (Young et al. 2013b, 2014a). This feature is an apomorphy of Ieldraan melkshamensis amongst Metriorhynchidae but, considering that every known Geosaurus specimen lacks preserved basioccipital tuberosities, we cannot discount the possibility that it is a shared feature of Geosaurina.

The dorsal and medial sides of the basioccipital are occupied by the occipital condyle. The hemispherical surface of this articulation is not completely smooth, and features a single pit, a characteristic that is also seen in other metriorhynchids (e.g. 'Mr Leeds' Dakosaur', NHMUK PV R 3321) but not in others ('Metriorhynchus' brachyrhynchus, NHMUK PV R 3804). The position and size of the pit appear to vary across the clade, and in NHMUK PV OR 46797 it sits in the dorsal half of the condyle. Further comparison is required to determine if this feature has any phylogenetic significance.

The foramen magnum is positioned above the occipital condyle and only its ventral margin is completely preserved. The basioccipital participates in the ventral rim of the foramen magnum through the dorsal extent of the occipital condyle. However, only a minor part of the rim $(\sim 30 \%$ of its length) is constituted by the basioccipital, the rest being bordered on both sides by the exoccipital-opisthotics.

In occipital view, the contact between the exoccipital and opisthotics passes diagonally through the lateral margin of the basioccipital tuberosities and cuts across to the top corner of the occipital condyle (Figs 2, 3E). The full extent of the exoccipital-opisthotics is not clear, as it is not discernible whether the exoccipital is fused to the opisthotics to form an otoccipital (also see Torvoneustes coryphaeus; Young et al. 2013a). The surface of the exoccipital-opisthotic complex is normally pierced by numerous cranial nerve and blood vessel foramina. In NHMUK PV OR 46797, only a pair of foramina (here identified as being for the hypoglossal nerves) is visible on both sides of the occipital condyle, ventral to the level of the foramen magnum ventral rim (Fig. 2). This opening is laterally aligned with the occipital condyle, and not dorsomedial to it, as in most metriorhynchids and thalattosuchians (Young et al. 2013a). This may be a diagnostic feature of Ieldraan melkshamensis among Thalattosuchia. However, although the position of this foramen is congruent with the same feature in other metriorhynchids, unless CT scans of a complete skull become available, it is difficult to compare with extant crocodylians, which have an osteological correlate for this nerve opening; thus, this can only be a hypothesis for the moment. On the right side, slightly ventrolateral to the hypoglossal opening, a channel for an unknown opening is preserved on both sides at the basioccipital-exoccipital suture (labelled as '?'), but we cannot describe it further due to damage in this area. A pair of foramina, roughly in the same area, is also reported in Torvoneustes coryphaeus (identified as "?" in Young et al. 2013a, fig. 8).

A large, flat surface is well exposed on the posterior/lateral sides of the squamosal and is situated above a welldeveloped crest that most likely is part of the paroccipital process of the opisthotic (Figs 1, 2). Pol \& Gasparini (2009) reported that this is a common feature of all thalattosuchians, although size and orientation are variable in Metriorhynchidae.

A broad arch with dorsal concavity is visible in occipital view. It is separated by a fracture from the main occipital surface, and sits in association with the supraoccipital, exoccipital and parietal (Figs 2, 3E). We identify this element as the left squamosal, which in life would have bordered the posterior rim of the supratemporal fenestra, sitting on top of the lateral expansion of the exoccipital.

What may be a large fragment of the supraoccipital is preserved above and slightly dislodged from the occipital condyle below the tilted parietal (Figs 2, 3H, I, K) It is crossed by a vertical crack that may represent a mid-line structure similar to the ridge visible in specimens referred to 'Metriorhynchus' brachyrhynchus (NHMUK PV R 3804). A small fragment of the parietal sits on top of it (well visible in lateral view in Figs 1, 3C). Given its fragmentary preservation, not much can be added to the description of these elements.

Mandible. The lower jaw is the best-preserved part of NHMUK PV OR 46797, probably because the calcite veins of the septarian nodule only partially reach this area (Fig. 3J, K). Only the left ramus is exposed, whilst the right one is probably still embedded in the concretion. Unfortunately, it cannot be easily accessed due to the weight, fragility and size of the specimen, so we have left it unprepared for the time being. Nevertheless, the left ramus is sufficiently informative to describe the lower jaw.

The left ramus of NHMUK PV OR 46797 is well exposed on its lateral side, and is only slightly deformed (Fig. 1). The majority of the anterior mandibular symphysis is not present, whilst its posterior section is exposed in ventral view on one side of the concretion. Most of the posterior dentary, the angular, surangular and splenial, 
and the contacts amongst these bones, can be confidently identified and described. The posterior extent of the angular and surangular are also missing, as is the retro-articular process. However, the triangular shape of the jaw section in occipital view (Fig. 2) indicates that the break must have occurred somewhere across the articular, posterior to the glenoid fossa (inaccessible because it is embedded in the matrix). The coronoid, articular, prearticular, and the entire medial side of the mandibular ramus are also impossible to access.

The mandible of Ieldraan melkshamensis would have been $\sim 60-65 \mathrm{~cm}$ long, with a moderately short and robust mandibular symphysis, and a deep posterior half with a prominent coronoid process lower than the level of the glenoid fossa. All of these features are apomorphies of Geosaurini and are linked to increased mechanical resistance, optimum gape angle and ultimately wide-gape macrophagy (Pol \& Gasparini 2009; Young \& Andrade 2009; Young et al. 2012a, b, 2013b).

A well-defined groove is developed across the dorsolateral side of the mandible. This structure is called the surangulodentary groove because it extends from the dentary to the surangular. Unfortunately, its anterior and posterior ends cannot be confidently identified due to poor preservation (Fig. 1). The preserved length of the surangulodentary groove is deeply excavated and well defined. This is another character that supports the affinity of Ieldraan melkshamensis with Geosaurini, as the groove is shallower and less clearly defined in Metriorhynchinae (Andrews 1913; Young et al. 2012b).

The lower jaw of NHMUK PV OR 46797 is weakly ornamented with the same bone texture of the skull, consisting of small oval pits and fine furrows, as in Geosaurus species (Young \& Andrade 2009).

The posterior and dorsal sides of the dentary are fragmented but well exposed in lateral view (Figs 1, 3J, K). As in all metriorhynchids, the dentary it is the main element of the lower jaw, occupying the anterior and dorsal side of the mandible. The anterior, dorsal and posterior parts of the dentary are poorly preserved. This makes it impossible to measure the length of the tooth row. The dentary contacts the surangular and angular posteriorly and the splenial ventrally (Fig. 3F). The dorsolateral margin of the preserved dentary bears well-developed reception pits for the maxilla and premaxilla teeth. This feature, combined with the tri-faceted/enlarged teeth, and the short interalveolar distance, shows that the maxillary dentition overbites the dentary dentition (see Dentition), as in Geosaurus (Young \& Andrade 2009; Andrade et al. 2010; Young et al. 2012a).

Posteriorly, the dentary reaches half of the estimated length of the lower jaw and is marked by a straight-anteriorly dipping suture with the surangular (Fig. 1). The relative position of this suture compared to the orbit is difficult to assess, but assuming that little relative movement occurred between the skull and lower jaws, it may be similar to the condition in Geosaurus. The position of the dentary and surangular suture has phylogenetic significance in Thalattosuchia. In Metriorhynchinae it extends beyond the orbit, whilst in Geosaurinae it generally sits in line with the orbital area. However, in Geosaurus giganteus (NHMUK PV R 1229; NHMUK PV OR 37020) the surangulardentary suture is approximately aligned with the anterior margin of the orbit (Young \& Andrade 2009).

The dentary contacts the angular with a wedge-shaped suture (Figs 1, 3F). The anterior extent of this suture marks the triple contact amongst the dentary, angular and splenial, which is normally hidden in lateral view but well exposed in NHMUK PV OR 46797 (likely due to postmortem deformation). The posterior part of the dentarysplenial suture is not visible in lateral view but can be seen in ventral view from the side of the boulder. In life, this contact would have been V-shaped, with the posterior extent of the mandibular symphysis occupied by the splenials (Fig. 3F, K). As previously mentioned, the posterior part of the dentary is sulcated by the anterior extent of the surangulodentary groove.

The splenial is the main element of the medial side of the mandible. It is partially exposed in ventral view on one side of the boulder (Figs 1, 3F, K). It sits in anatomical association with the remaining elements of the lower jaw. In thalattosuchians, the splenial always participates in the symphyseal suture in both dorsal and ventral views (Andrews 1913). Its involvement is generally extensive in metriorhynchids, where the splenial normally accounts for more than $20 \%$ of the entire length.

In ventral view, each splenial appears as an anteroposteriorly elongated triangle (Fig. 3F). The anterior process tapers in between the midline interdentary suture with the other side splenial and the dentary dorsally. The posterior end of the splenial-splenial suture marks the end of the mandibular symphysis and is the point where the divergence of the mandibular rami begins (Fig. 3F). Crucially, this point is visible in NHMUK PV OR 46797 and, combined with our estimate of mandibular length, allows calculation of the symphyseal area proportions. We estimate it to be $\sim 25-30 \mathrm{~cm}$ long ( $\sim 40 \%$ of the mandibular length), with the splenial involved for at least $50 \%$ of the symphysis length along the ventral midline. However, given the uncertainty of these estimates we decided against implementing these characters in our phylogenetic dataset.

The surangular occupies the posterodorsal part of each mandibular ramus, and in NHMUK PV OR 46797 is not as well preserved as the dentary and angular (Fig. 1). Specifically, the eminence of the coronoid process was diagenetically broken and folded over onto the lateral surface of the surangular, but it is still visible projecting outside the dorsal margin of the lower jaw (Fig. 1). Several fractures eroded the superficial layer of the posterior surangular, but the remaining parts are enough to reveal that the 
ornamentation of this bone does not substantially differ from the rest of the mandible and skull. The surangularangular suture can be easily identified and is also highlighted by a change of direction of the ornamental oval pits and grooves on the two bones. This suture describes a long, weakly dorsally concave curve. The surangular appears to be not as long and deep as in other metriorhynchids, although this may an artefact of deformation and preservation. Among metriorhynchids, Geosaurus also has a relatively small surangular (Young \& Andrade 2009), suggesting this feature could be an apomorphy of Geosaurina.

The angular is the mandibular bone ventral to the surangular and posterior to the dentary, and constitutes the posterior and ventral part of each mandibular ramus (Fig. 1). Its posterior ventral margin is weakly curved in lateral view, as in Geosaurus but opposed to the condition in Tyrannoneustes lythrodectikos (Young \& Andrade 2009; Young et al. 2013b; Foffa \& Young 2014) in which it is strongly curved, raising the glenoid fossa above the coronoid process. The anterior extent of the angular is a wedge-shaped process delimited by the dentary in dorsal view and by the splenial in ventral view. The latter contact excludes the angular from participating in the symphyseal suture (Figs 1, 3F).

Dentition. Ieldraan melkshamensis has thecodont tooth implantation (Figs 1, 4). This is evident in NHMUK PV OR 46797, even though all of the teeth are preserved only in labial view. There are a few consecutive tooth crowns emerging from the left premaxilla/maxilla and the middle section of the left dentary. The interalveolar spacing between them is small (generally less than half the alveolar distance), similar to Geosaurus spp. and other geosaurins (Wilkinson et al. 2008; Young et al. 2012a, b).

In total, there are 11 visible crowns, of which five are well preserved. They are single cusped and bicarinate, with macroscopic strongly keeled carinae, which are particularly prominent in the apical half. The carinae are denticulate. These denticles are microscopic, nearly contiguous (yet unevenly distributed, often in aggregates of 5-10 denticles), isomorphic, unequally sized and poorly developed (not exceeding $300 \mu \mathrm{m}$ ). This corresponds to microziphodonty sensu Andrade et al. (2010) (Fig. 4) (but see Discussion). The denticles of Ieldraan melkshamensis are not homogeneous, but vary in size and shape. This is also observed in the geosaurine 'Metriorhynchus' brachyrhynchus and basal geosaurin Tyrannoneustes lythrodectikos (Young et al. 2013b; Foffa \& Young 2014), and differs from Geosaurus spp. (Andrade et al. 2010) in which the denticles are better defined and more tightly packed.

Geosaurus spp. and Ieldraan melkshamensis have tooth crowns whose labial surfaces are divided into three apicobasal planes. However, uniquely among Metriorhynchidae,
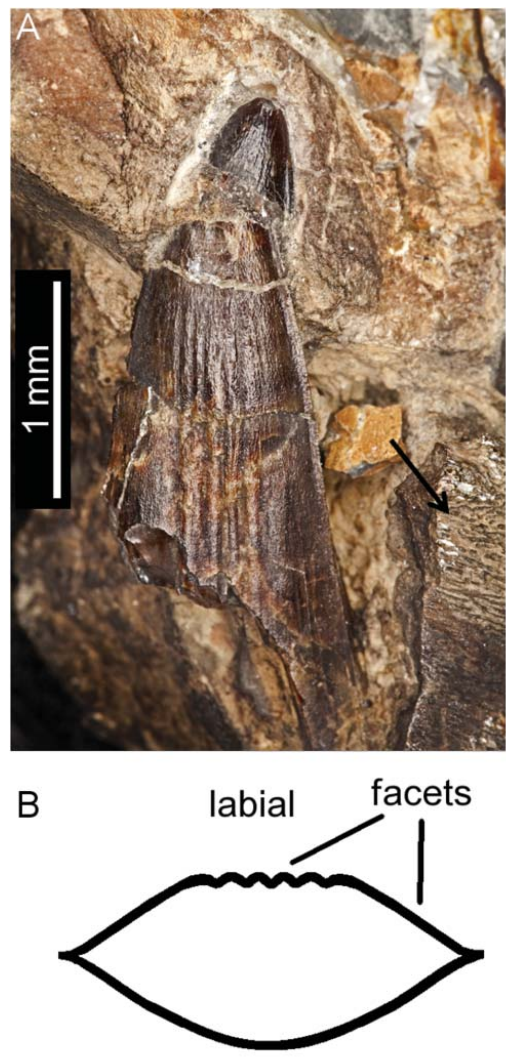

lingual

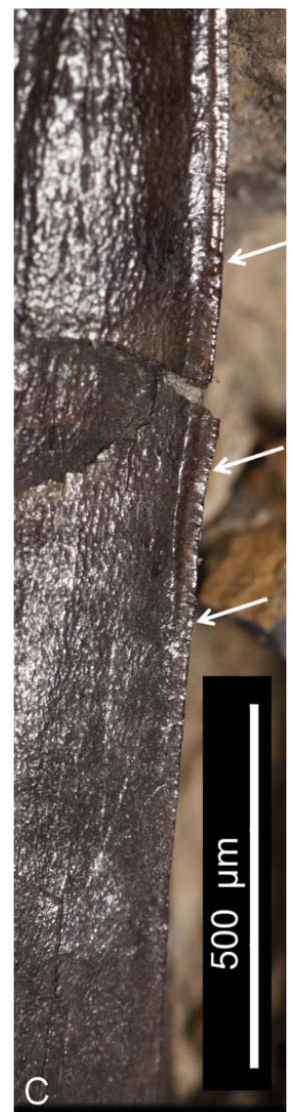

Figure 4. Close-up of a dentary tooth of Ieldraan melkshamensis gen. et sp. nov. (NHMUK PV OR 46797). A, dentary tooth in labial side with detail of bone texture (black arrow); B, schematic cross-section of a tooth; $\mathbf{C}$, dentary tooth close-up showing the carina and denticles (white arrow) in labial side.

in NHMUK PV OR 46797 the middle plane is clearly fluted - sculpted by well-developed troughs/flutings separated by broad continuous, parallel and well-developed ridges with a convex/flat profile (Fig. 4B). The number of troughs (five) is constant across the dentition, although it bears repeating that only a few teeth are preserved. The functional significance of this character, if any, is not clear. The consistent morphology, and absence of breaks, show that this feature is not diagenetic.

The troughs and the round-convex ridges between them that form the fluted surface should not be mistaken with the ornamentation of the crowns. The ornamentation proper is composed of small, densely packed, discontinuous and poorly organized ridges that give the crown a rough texture to the enamel. These ridges gradually increase in size towards the apex of each tooth. The dentine ornamentation does not interact with the carinae; although the rugosity pattern approaches them, it stops before creating any false serration morphology (Fig. 4A, B) (Young et al. 2014b). However, both ornamentation patterns interact with the fluted middle surface of the 
crown, as shown in Figure 4. This pattern contrasts with all Geosaurus specimens, in which the crowns are largely unornamented on the labial surfaces. The only Geosaurus specimen with dentition that has observable lingual surfaces is an undescribed Geosaurus sp. from the Tithonian of England (MJML K461). Further investigation is ongoing to assess whether this specimen belongs to any known species of Geosaurus. Nevertheless, the labial sides of the teeth of MJML K461 are ornamented with fine apicobasal parallel ridges that do not extend further than half the apicobasal length of the crown.
The occurrence of troughs on the teeth is an extremely rare feature in Metriorhynchidae, but is not exclusive to Ieldraan melkshamensis. Two geosaurine specimens NHMUK PV R 3804 (the holotype of 'Metriorhynchus' cultridens) and an undescribed geosaurin PETMG R248 (both from the Peterborough Member of the OCF) - also have teeth with fluting structures on the labial surface (Fig. 5B-D). It is important to state that the dental and cranial morphologies of these specimens - which probably belong to the same taxon - are clearly distinct from NHMUK PV OR 46797. In particular, the teeth of both

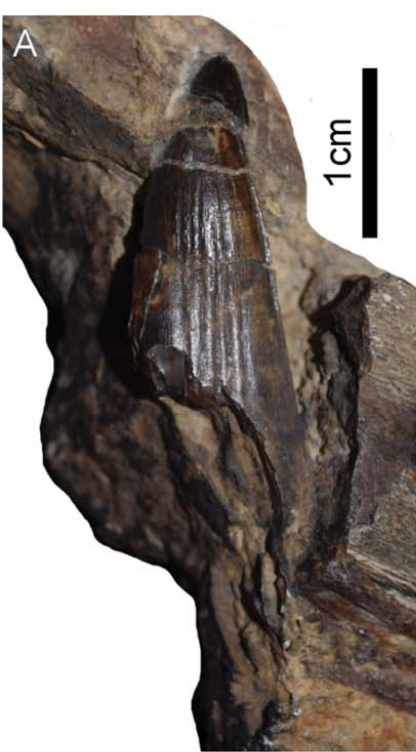

B
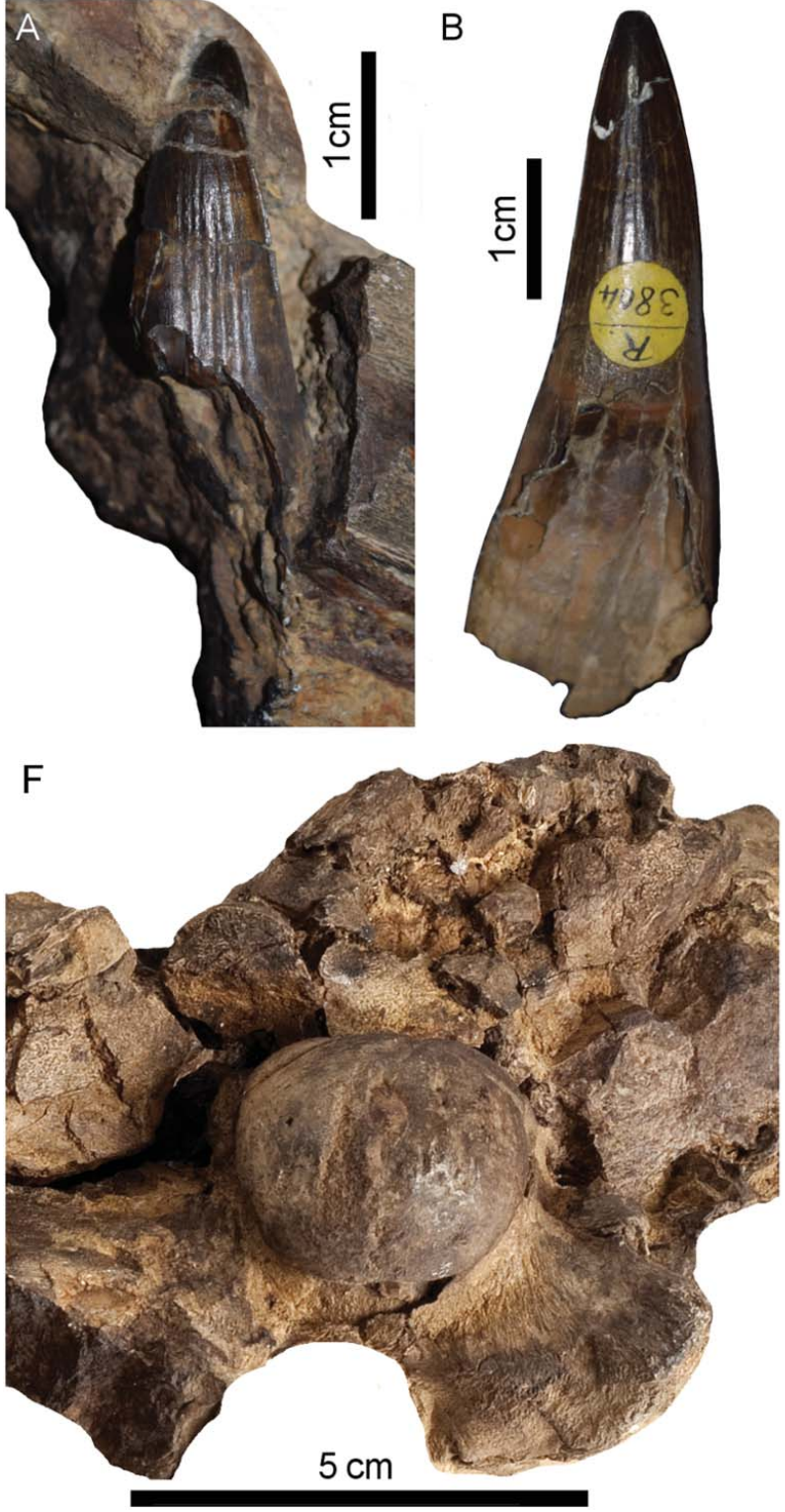
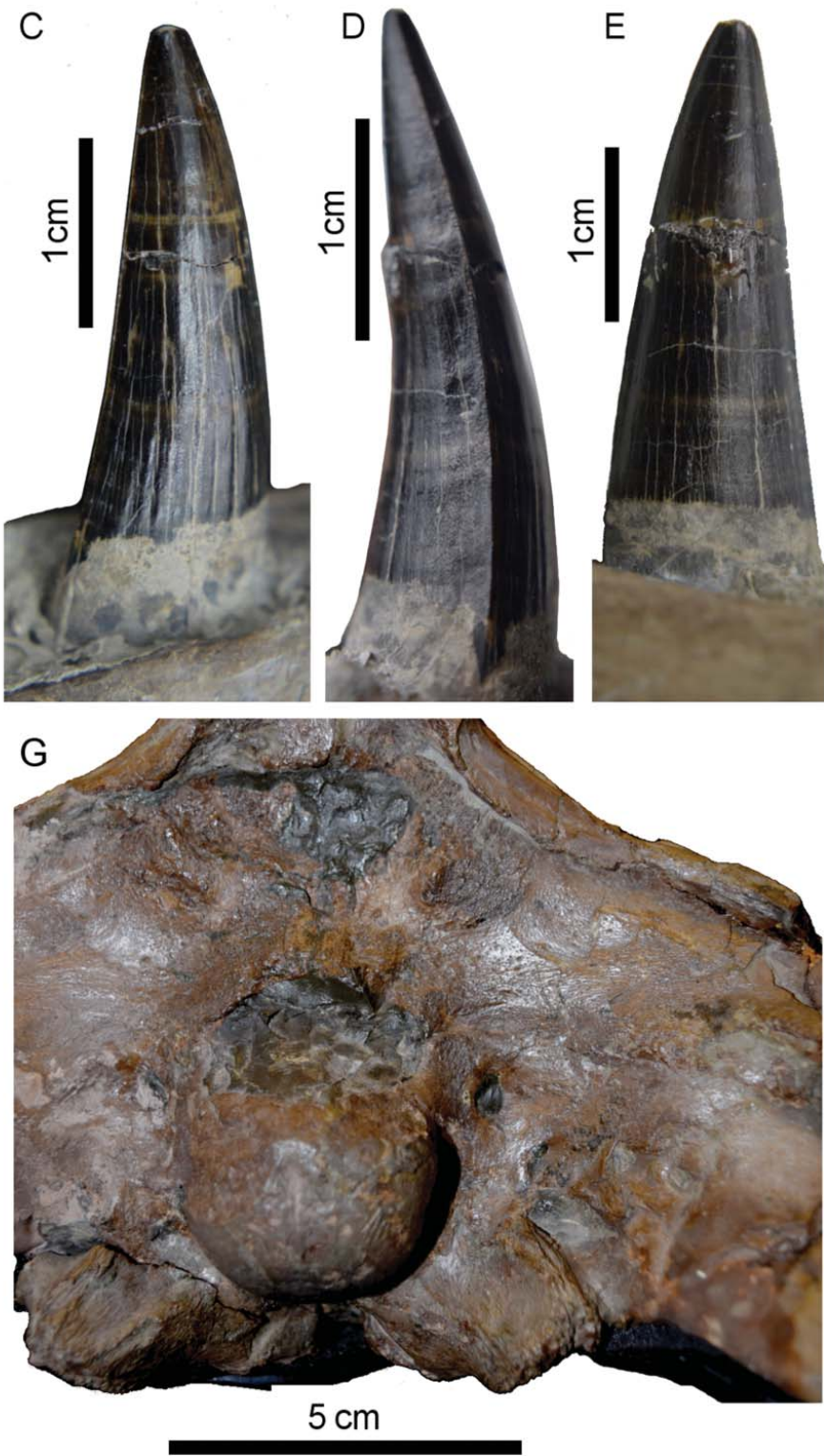

Figure 5. Comparative plate of fluted teeth and basal tuberosities in geosaurin taxa. A, Ieldraan melkshamensis (NHMUK PV OR 46797), dentary tooth; B, 'Metriorhynchus' brachyrhynchus (NHMUK PV R 3804), isolated tooth; C, indeterminate geosaurin (PETMG R248) in labial view; D, indeterminate geosaurin (PETMG R248) in carinal view; E, indeterminate geosaurin (PETMG R248) in lingual view; note the different flutings and carinal morphology; F, occipital view of Ieldraan melkshamensis (NHMUK PV OR 46797) basioccipital; G, occipital view of 'Metriorhynchus' brachyrhynchus (NHMUK PV R 3804) basioccipital. Note the difference in relative size between the basal tuberosities of I. melkshamensis and 'M.' brachyrhynchus. 
Table 1. The craniomandibular and dental differences between 'Metriorhynchus' brachyrhynchus (PETMG R248 and NHMUK PV R 3804) and Ieldraan melkshamensis (NHMUK PV OR 46797).

\begin{tabular}{lll}
\hline & 'Metriorhynchus' brachyrhynchus & Ieldraan melkshamensis \\
\hline Skull roof ornamentation & $\begin{array}{c}\text { Conspicuous, made by medium sized pits and } \\
\text { shallow to deep furrows. } \\
\text { Mandible ornamentation } \\
\begin{array}{c}\text { Conspicuous, made by medium sized pits and } \\
\text { shallow to deep furrows. } \\
\text { tuberosity size }\end{array}\end{array}$ & $\begin{array}{l}\text { Inconspicuous, numerous very small oval pits, very } \\
\text { rare furrows. } \\
\text { Inconspicuous, numerous very small oval pits. }\end{array}$ \\
$\begin{array}{l}\text { Dentition } \\
\text { Strongly laterally compressed, unornamented on } \\
\text { both sides. The enamel appears smooth on both } \\
\text { sides. }\end{array}$ & $\begin{array}{c}\text { Greatly enlarged } \\
\text { Enlarged crowns, laminar, tri-facets on the labial } \\
\text { side. Weakly ornamented by non-continuous } \\
\text { apicobasal ridges visible on the apical half. The } \\
\text { enamel has a rough appearance. }\end{array}$ \\
Flutings & $\begin{array}{l}\text { Not prominent. } \\
\text { Poorly defined, non-parallel, unequal in length, } \\
\text { usually more than five. Not present in all present } \\
\text { crowns. }\end{array}$ & $\begin{array}{c}\text { Very prominent, especially on the apical half. } \\
\text { Well defined, exclusively on the middle facet of the } \\
\text { crowns, always three ridges and five troughs. } \\
\text { Present in all preserved crowns. }\end{array}$ \\
\hline
\end{tabular}

NHMUK PV R 3804 and PETMG R248 are indistinguishable from each other (Fig. 5). The crowns are single cusped, moderately enlarged (up to nearly $3 \mathrm{~cm}$ in apicobasal length), laterally compressed, and have a high crown height/length ratio (up to 2.8). The D9 tooth in PETMG R248, and some isolated NHMUK PV R 3804 teeth, have weak ornamentation and troughs on their labial side, and no enamel ridges (shallow or high-relief) can be seen on the lingual surface (Fig. 5D, E).

The similarities between PETMG R248 and NHMUK PV R 3804 and Ieldraan melkshamensis are limited to the fluted tooth crowns (Table 1). Without verging into detailed cranial descriptions of PETMG R248 and NHMUK PV R 3804 , their lower jaws, skulls and dentitions are very different from NHMUK PV OR 46797 in morphology and ornamentation (Tables 1, 2; Fig. 5). In particular, the teeth of PETMG R248 and NHMUK PV R 3804 lack apicobasal facets on the labial surface; the carinae are not as prominent as in Ieldraan melkshamensis and bear well-formed isomorphic microscopic denticles that are non-contiguous along the entire carinae (Fig. 5D compared to Fig. 4). The flutings differ from those seen in Ieldraan melkshamensis in being less well defined and having generally more than five per tooth developed all around the labial surface and decreasing in apicobasal length approaching the carinae (conversely Ieldraan consistently has five parallel troughs which are all of the same length) (Fig. 5A-C). Notably, the flutings cannot be seen in all of the teeth of PETMG R248 and NHMUK PV R 3804, and we cannot exclude that they are restricted to those from the anterior dentary (the only tooth in situ for those two specimens is the D9 tooth of PETM R248). In summary, the combinations of these features and very distinct cranial morphology and ornamentation clearly demonstrate that these specimens cannot be referred to Ieldraan (Tables 1, 2).
Remarks. Unfortunately, there is no postcranial material associated with the specimen, so we can only rely on the incomplete basicranial length for estimating total body length. Based on the better preserved mandibular ramus we estimated a range of potential basicranial length of approximately 55-60 cm for NHMUK PV OR 46797, which using the Young et al. (2011b) body length equations, corresponds to a total body length of 2.95-3.22 m. This is comparable to the largest known Geosaurus specimen - a skull referred to G. giganteus, NHMUK PV OR 37020 - of approximately $3 \mathrm{~m}$ in total body length. However, considering the distortion that the specimen has undergone, we recommend caution using these estimates in quantitative analyses.

\section{Phylogenetic analysis}

We tested the phylogenetic relationships of Ieldraan melkshamensis using a slightly modified version of the second dataset of Young et al. (2016) (Fig. 6). The dataset comprises 104 crocodylomorph OTUs (of which 65 are thalattosuchians, including 41 metriorhynchoids) scored for 298 characters. Compared to the previous version, our new dataset includes some modified scores for Ieldraan melkshamensis (which was included in the previous version, where it was labelled as 'Melksham Monster') based on our study of the specimen (see Supplemental material). Despite its poor preservation, Ieldraan melkshamensis is scored for 44 out of 298 characters (14.8\%).

The parsimony analysis of the dataset was conducted using TNT 1.5 (Willi Hennig Society Edition; Goloboff et al. 2008). We followed the procedure of Young et al. (2016) using the 'New Technology search' option in TNT (Sectorial Search, Ratchet, Drift, and Tree fusing) with 


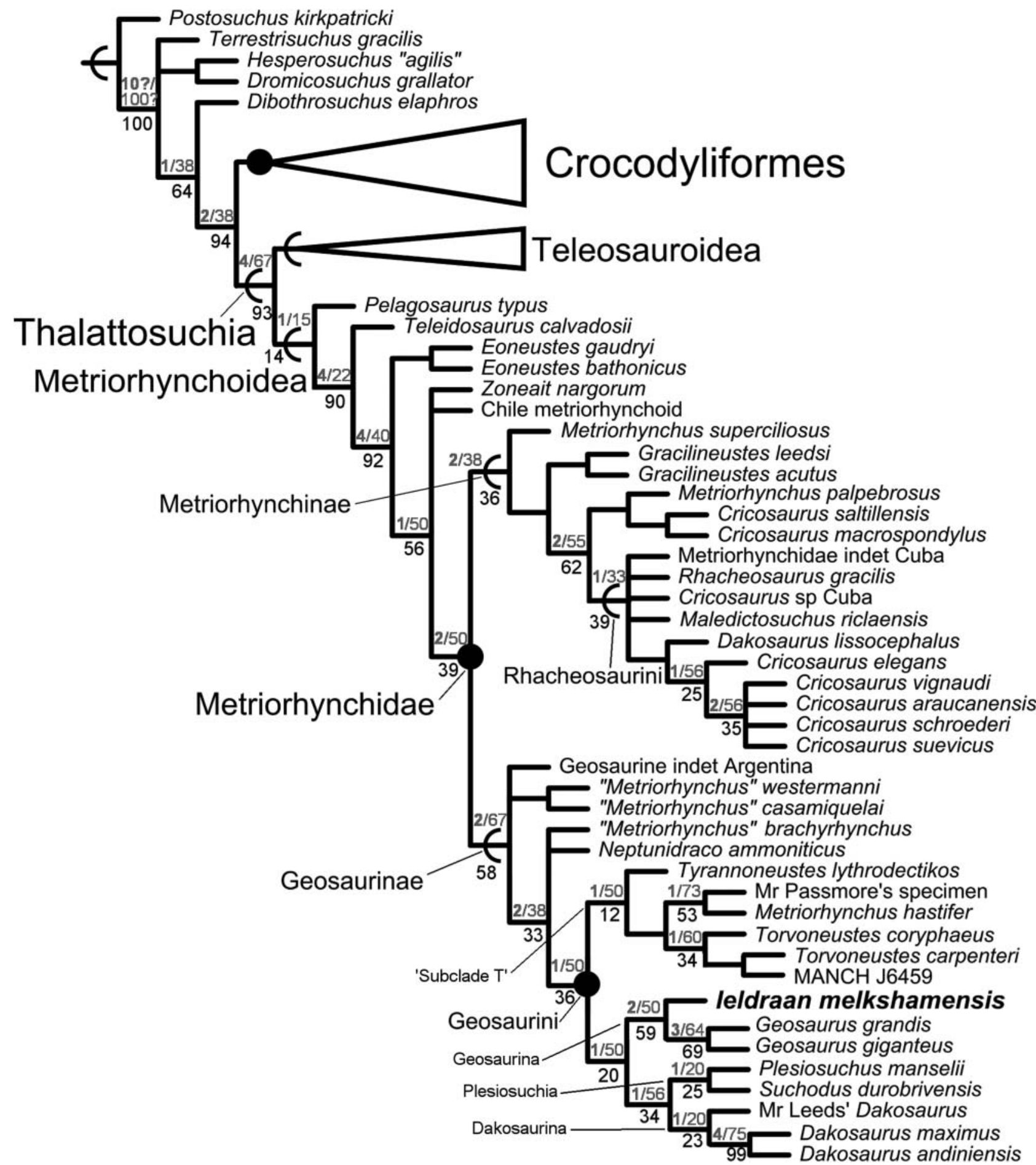

Figure 6. Simplified strict consensus tree of the 234 most parsimonious cladograms of Metriorhynchidae within Crocodylomorpha. Bootstraps values are reported below each node; absolute/relative Bremer support values are reported above each node in grey. Length $=944$ steps $; \mathrm{CI}=0.413 ; \mathrm{RI}=0.827 ; \mathrm{CR}=0.341 ; \mathrm{HI}=0.587$.

1000 random-addition replicates (RAS). We increased to 1000 the iterations of each method: in the Sectorial Search 1000 Drift cycles (for selections of above 75) and 1000 starts and fuse trees 1000 times (for selections below 75); 1000 rounds of Consensus Sectorial Searches (CSSs) and Exclusive Sectorial Searches (XSSs). Ratchet 1000 ratchet iterations set to stop the perturbation when 1000 substitutions were made or $99 \%$ of the swapping was reached Drift: 1000 Drift cycles also set to stop the perturbation when 1000 substitutions were made or $99 \%$ of the 
swapping was reached. We set three rounds of Tree fusing.

Similarly, we used the same method described in Young et al. (2016) to calculate nodal support. Non-parametric bootstrapping was once again run using 'New technology search' option with 1000 replicates using 100 RAS for the following advanced search methods. Sectorial Search: 100 sectorial search drifting cycles for selections of above 75; 100 start trees and fused trees 100 times below 75, with 100 rounds of CSSs and XSSs. Ratchet: 100 Ratchet iterations, with the perturbation phase set to stop when 100 substitutions were made or when $99 \%$ of the swapping was completed. Drift: 100 cycles of Drift, which would stop the perturbation phase when 100 substitutions were made or when $99 \%$ of the swapping was complete. Finally, we set three round of Tree fusing.

The time-calibrated strict consensus trees of Geosaurinae (Figs 7,8) were produced using the package 'strap' in R (R Core Team 2013; Bell \& Lloyd 2015).

\section{Results}

The analysis produced 234 most parsimonious cladograms (length $=944$ steps; consistency index $(\mathrm{CI})=0.413$; retention index $(\mathrm{RI})=0.827$; consistency ratio $(\mathrm{CR})=$ 0.341 ; homoplasy index $(\mathrm{HI})=0.587)$, the strict consensus of which gave the same topology as that reported by Young et al. (2016) (Fig. 6). As such, our re-scoring of Ieldraan melkshamensis has not altered its phylogenetic position. Therefore, we focus solely on the Metriorhynchidae and Geosaurinae part of the topology (for discussion on the entire topology, consult the results and discussion sections of Young et al. 2016). Thalattosuchia is recovered as sister group to Crocodyliformes, as was suggested by Wilberg (2015), and is also found to be monophyletic and further subdivided into two monophyletic groups,
Teleosauroidea and Metriorhynchoidea. Within the latter group, Zoneait nagorum is in a polytomy with a metriorhynchoid from Chile and Metriorhynchidae (see Wilberg 2015; Young et al. 2016). In Metriorhynchidae, the subfamilies Metriorhynchinae and Geosaurinae are recovered, and so is the tribe Geosaurini within the latter subfamily. Ieldraan melkshamensis is deeply nested within Geosaurinae as the most basal and oldest member of Geosaurina, which also includes two species of Geosaurus.

\section{Discussion}

Middle Jurassic origin of all geosaurin groups

There are four major lineages of geosaurins, each of which leads to a particular derived taxon: Torvoneustes, Plesiosuchus, Dakosaurus and Geosaurus (Figs 6, 7, 8). Our phylogenetic analysis shows that all four of these lineages were already present in the Callovian. Key to this discovery is the reassessment and phylogenetic position of the most basal members of these respective lineages: Tyrannoneustes lythrodectikos, Suchodus durobrivensis, 'Mr Leeds' Dakosaur' (NHMUK PV R 3321), and now Ieldraan melkshamensis. This ongoing work has radically changed our understanding of geosaurin evolution. Before the description of the oldest known geosaurin Tyrannoneustes lythrodectikos (OCF, Callovian) (Young et al. 2013b), the oldest member of the Geosaurini clade was Late Jurassic in age. Subsequently, Tyrannoneustes lythrodectikos was found to be the sister taxon to Geosaurini, pushing the origin of wide-gape macrophagy back by at least $10 \mathrm{Ma}$, into the late Middle Jurassic (Young et al. 2013b). Before the current paper, the early Kimmeridgian was the earliest time during which there was evidence that the four geosaurin lineages had definitely split (Young et al. 2014c). Recent re-evaluations of several misinterpreted Callovian

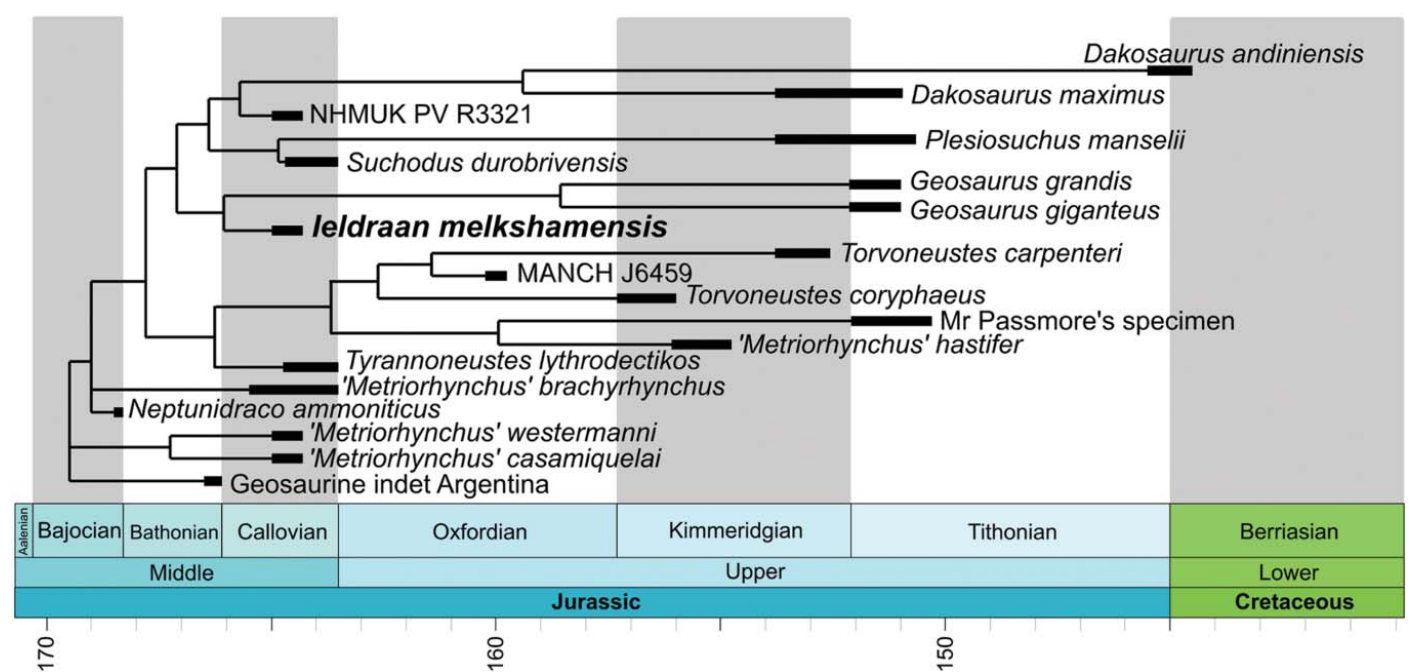

Figure 7. Time-calibrated phylogenetic tree of Geosaurinae. 
specimens - and their inclusion as OTUs in phylogenetic analyses - has now changed this view (Fig. 8).

The phylogenetic analysis of Young et al. (2016) was the first to suggest Geosaurini originated in the late Middle Jurassic. Tyrannoneustes lythrodectikos was found to be a member of Geosaurini rather than its sister taxon, and several other poorly studied OCF taxa were found to be members of Geosaurini. Our rescoring of the 'Melksham Monster' (as Ieldraan melkshamensis was called by Young et al. (2016)) based on our detailed study of the specimen (which itself was predicated by the detailed preparation of the material) has not changed the internal relationships of Geosaurini. However, our analysis does present a new evolutionary arrangement for macrophagous metriorhynchids. Geosaurini is found to be monophyletic, and split into two monophyletic groups (Figs 6-8). Group one ( = 'subclade T') has the Callovian Tyrannoneustes as the basalmost taxon, with a derived Late Jurassic subclade consisting of 'Metriorhynchus' hastifer + Torvoneustes. Group two comprises Geosaurina, Plesiosuchia and 'Dakosaurina'. Geosaurina is found as the sister taxon to a clade of broad-short snouted geosaurins (Plesiosuchia and 'Dakosaurina'). The different position of Tyrannoneustes and the phylogenetic affinities of Ieldraan melkshamensis both have crucial consequences for the time and mode of diversification of Geosaurini.

In particular, the sudden Late Jurassic diversity of macrophagous geosaurins now appears less abrupt than previously suggested, as we now know that it had a long phylogenetic and temporal fuse. Undeniably, geosaurins still constituted a very small component (taxic and numerical; see also Young 2014) of the late Middle Jurassic ecosystems, but the new discoveries suggest that all the major groups - once supposed to be exclusively Late Jurassic were already present approximately $10 \mathrm{Ma}$ before the previous estimates. This also means that most of the key macrophagous adaptations known in Kimmeridgian-Tithonian taxa were already present in the Callovian. Yet the mechanisms that turned the Middle Jurassic metriorhynchine/teleosaurid-dominated thalattosuchian fauna of the OCF to the Late Jurassic geosaurin-dominated fauna in the Kimmeridge Clay Formation are still unknown (see Young 2014). The reason for this is that the Callovian-Kimmeridgian transition was a time of deep faunal turnover in marine ecosystems - severely affecting all the marine amniote groups (Benton \& Spencer 1995; Young 2014; Foffa et al. 2015). Unfortunately, our understanding of this subject is hampered by the poor fossil record of the intermediate layers of the Oxfordian (the so-called 'Corallian Gap', Young 2014).

\section{Evolution of ziphodonty dentition in Geosaurini}

The evolution of ziphodonty in Geosaurinae has been extensively studied (Andrade et al. 2010; Young et al. 2012a, b, 2013b). Here we update this topic in the light of new data, our description of the Ieldraan melkshamensis holotype, and our phylogenetic analysis (Table 2; Fig. 8). In doing this, we adopt a nomenclature that in our view has the merit of taking into account the functionality of each morphological type of serration (Table 2). Two distinct characteristics must be considered when describing true ziphodonty: (1) denticle development that describes the size and how clearly defined denticles are (e.g. incipient, poorly developed, well developed); and (2) denticle arrangement along the carinae (e.g. do they form a contiguous row along the carinae, or are they simply forming short (2-10) repeat units?). These terms must not be confused, as they describe different aspects of denticle morphology. Specifically, it is the co-occurrence of the different states of denticle development and arrangement that regulate the presence or absence of 'functionally' serrated edges (see Table 2). As a clear nomenclature is essential to capture precisely the morphological and functional differences among the variety of ziphodont dentitions in Geosaurinae, we summarize the fundamental definitions in the next section.

Ziphodonty is defined "as dentitions where all teeth possess denticulated carinae, comprised of true denticles" (Andrade et al. 2010; based on Prasad \& Broin 2002). We adopt the terms 'false serrations' and 'true denticle' with the same meaning as introduced by Prasad \& Broin (2002). Macroziphodonty, microziphodonty and 'incipient (micro)ziphodonty' were defined in Young et al. (2013b). The latter was introduced to cover those morphologies where the denticles were poorly defined and/or the denticles do not form a contiguous row along the keel. These definitions are based on external morphologies rather than internal ones, i.e. denticles are serrations in which the dentine also contributes.

The most derived geosaurin taxa (Torvoneustes, Plesiosuchus, Dakosaurus and Geosaurus) have distinct serration morphologies, which are perhaps linked to functional partitioning of resources (Andrade et al. 2010; Young et al. 2012a, b, 2013b). Indeed, the phylogenetic position and dental morphology of Ieldraan melkshamensis (and recently added basal members of each lineage) help to explain the occurrence of four different serration morphologies in Geosaurini. The evolutionary history of these characters has been long debated, and to date can be summarized using two alternative scenarios:

1. Functional true ziphodonty evolved at the base of Geosaurini. In this hypothesis, true ziphodonty (i.e. presence of well-developed denticles that are contiguous along the carinae) would have followed different evolutionary trajectories (perhaps because of different mechanical/feeding-related needs) in Torvoneustes, Geosaurus, Dakosaurus and Plesiosuchus (Pol \& Gasparini 2009; Young \& Andrade 2009; Andrade et al. 2010; Young et al. 2012b,
04 
New Middle Jurassic metriorhynchid crocodylomorph

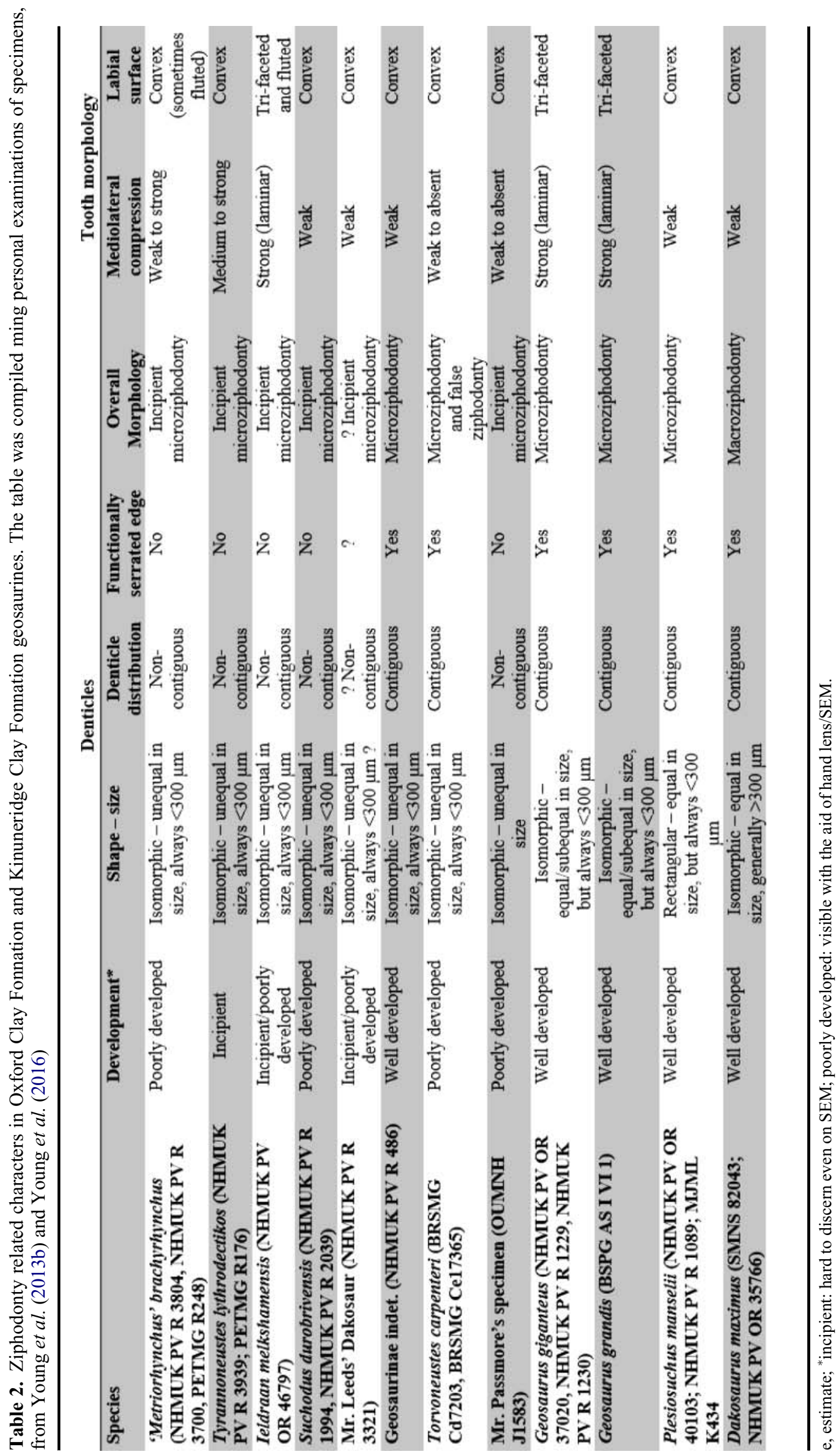



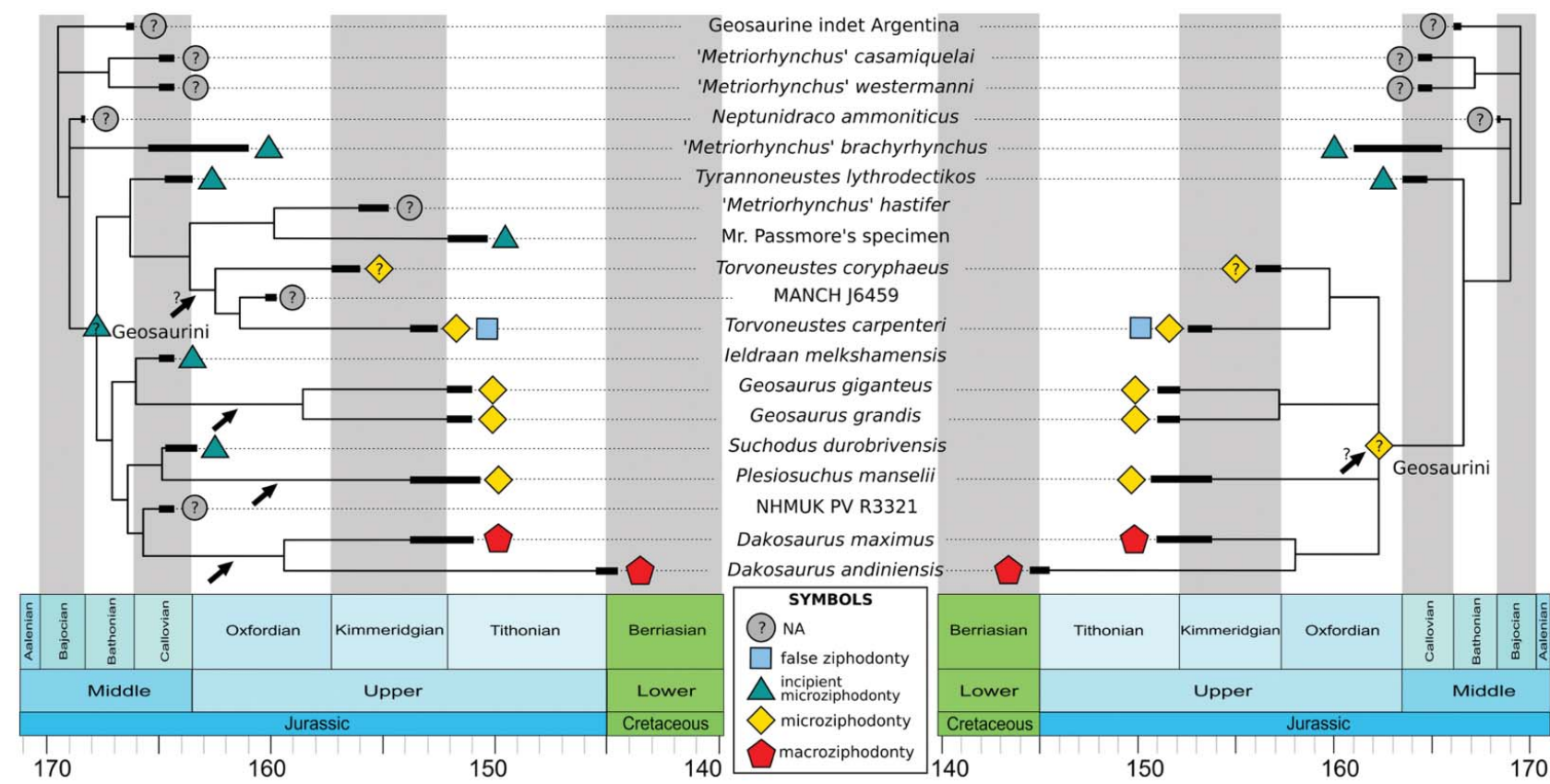

Figure 8. Time-calibrated cladograms of Geosaurinae with mapped different ziphodonty morphologies. Our tree (left) is compared to the modified topologies found by Young (2014) and Young et al. (2013b) (right). Note how the addition of new Middle Jurassic OTUs improves the resolution of Geosaurini internal relationships and changes understanding of the time and mode of ziphodonty evolution within the group. The black arrows indicate the lineages where ziphodonty was acquired.

2013a). In this scenario, the most recent common ancestor of Geosaurini had functionally serrated carinae (microziphodonty).

2. True, functional ziphodont carinae evolved independently at least four times in Geosaurini, once in the Geosaurus lineage, once (or perhaps twice, pending reassessment of Suchodus durobrivensis) in the Dakosaurus and Plesiosuchus subclade, and finally in Torvoneustes. In this scenario, the most recent common ancestor of Geosaurini did not have functionally serrated carinae but poorly developed, non-contiguous denticles on the carinae ('incipient' microziphodonty).

Our description of Ieldraan melkshamensis combined with the phylogenetic analysis of Young et al. (2016) helps us to discriminate between these hypotheses. While both can explain the evolution of the very different denticle morphologies in derived Geosaurini genera, we argue that the dental features of Ieldraan melkshamensis, (and indeed Tyrannoneustes lythrodectikos, Suchodus durobrivensis and 'Mr. Leeds' Dakosaur') better support the second hypothesis (Fig. 8).

First, the closest sister taxon to Geosaurini is 'Metriorhynchus' brachyrhynchus, a non-geosaurin geosaurine from the Callovian. This species has microscopic, poorly formed denticles, which are not contiguous (Figs 5, 8; Tables 1, 2) (Young et al. 2013b). Unfortunately, no information is available for other non-geosaurin geosaurines (Fig. 8).
Tyrannoneustes lythrodectikos, previously considered to be the sister taxon to Geosaurini, is now found to be a basal member of a large subclade including Torvoneustes (Young et al. 2016) (Figs 6-8). However, the dentition of Tyrannoneustes is similar to 'Metriorhynchus' brachyrhynchus in having poorly developed, non-contiguous microscopic true denticles (Young et al. 2013b). Similarly, the denticles of Ieldraan melkshamensis are also poorly developed, irregularly spaced along the carinae, and do not form a clear serrated edge (so that they do not alter the height of the keel; sensu Young et al. 2013b). Macrophotographs (Fig. 4) clearly show that the denticles of Ieldraan melkshamensis were less developed than those of Geosaurus (Geosaurus sp., SMNS 81834 and MJML K461; G. grandis, BSPG AS-VI-1; G. giganteus, NHMUK PV OR 37020) (Young \& Andrade 2009; Andrade et al. 2010) (Table 2).

The most striking consequence of this re-evaluation is that the basalmost members of two geosaurin lineages (Tyrannoneustes and Ieldraan) have 'incipient', non-contiguous microziphodont dentition. In other words, OCF geosaurin taxa had poorly developed (unevenly sized), non-contiguous and microscopic $(<300 \mu \mathrm{m})$ denticles that do not form a functional serrated edge along the carinae (Andrade et al. 2010; Young et al. 2013b). The notable exception to this is NHMUK PV R 486, the oldest known Dakosaurus-like tooth, discovered in an unknown horizon of the OCF (Young et al. 2013b, fig. 2). The carinae on this tooth have the homogeneous, isomorphic, and closely packed denticles that are characteristic of Geosaurus, Plesiosuchus and 
Dakosaurus (Andrade et al. 2010). Within this context, Torvoneustes, however, has a unique functional ziphodont morphology, in which the denticles are contiguous along the carinae but are poorly defined (Andrade et al. 2010; Barrientos-Lara et al. 2016). Two species, Torvoneustes carpenteri and T. mexicanus, have true ziphodonty and false ziphodonty, with the superficial enamel ornamentation contacting the carinal keel (Andrade et al. 2010; Young et al. 2013b; Barrientos-Lara et al. 2016). Interestingly, the geologically oldest Torvoneustes species, T. coryphaeus, does not have teeth with the enamel ornamentation contacting the keel (Young et al. 2013a).

Therefore, the plesiomorphic condition in Geosaurini could be poorly developed, non-contiguous microscopic denticles ('incipient' microziphodonty). This condition would have given rise to at least three independent true ziphodont morphologies, namely once in Torvoneustes, once in Geosaurus, and once (or twice?) in the Dakosaurus + Plesiosuchus subclade (Fig. 8). Future discoveries and redescriptions of key specimens are currently underway, and, coupled with an improved species-level phylogeny, will allow us further to test the two hypotheses of dental evolution in Geosaurini.

\section{Conclusions}

Based on our description of a long overlooked and misinterpreted specimen (NHMUK PV OR 46797), we establish the new taxon Ieldraan melkshamensis gen. et sp. nov. Despite the poor state of preservation, we demonstrate that this late Middle Jurassic taxon from the OCF shows remarkable similarities with the Late Jurassic genus Geosaurus. Ieldraan and Geosaurus are found to be sister taxa in a new European endemic, Callovian-Valanginian geosaurin lineage that we name Geosaurina subtr. nov. The morphology and stratigraphical occurrence of Ieldraan melkshamensis, combined with our phylogenetic analysis, demonstrate that numerous adaptations linked to macrophagy had already evolved in Geosaurini by the Callovian stage. This suggests that the diversification of the tribe was perhaps less abrupt than previously thought, but rather had a longer temporal and phylogenetic fuse. We also show that the evolution of ziphodonty followed a different path than previously hypothesized. The new information presented here indicates that four different true ziphodont morphologies in the derived Late Jurassic geosaurins independently evolved from a unique non-func-

\section{Acknowledgments}

We thank Deborah Hutchinson and Isla Gladstone (BRSMG), Matthew Riley (CAMSM), Paul Tomlinson (DORCM), Neil Clark (GLAHM), Mark Evans (LEICT), Steve Etches (MJML), Eliza Howlett and Hilary Ketchum

(OUMNH) and Glenys Wass (PETMG) for access and guidance during DF's visit to museum collections. DF's museum visits were funded by the Small Grant Scheme '2015 Wood Award' (PASW201402), Richard Owen Research Fund of the Palaeontographical Society, and the Systematics Research Fund. SLB is supported by a Marie Curie Career Integration Grant (630652) and his work on thalattosuchian cranial morphology is supported by Royal Society Research Grant RG130018. We are also grateful to the NHMUK Image Resources for the photographs of the described specimen. DF would finally like to thank R. E. Bartlett, B. A. Clarke and S. L. Shelley for the useful comments, discussion and assistance with software, which greatly helped the completion of this project. Finally, we are grateful to the comments and thorough reviews of two anonymous reviewers and the editor which considerably improved the quality of the manuscript.

\section{Supplemental data}

Supplemental material for this article can be accessed at: https://doi.org/10.1080/14772019.2017.1367730.

\section{References}

07

Andrade, M. B., Young, M. T., Desojo, J. B. \& Brusatte, S. L. 2010. The evolution of extreme hypercarnivory in Metriorhynchidae (Mesoeucrocodylia: Thalattosuchia) based on evidence from microscopic denticles morphology. Journal of Vertebrate Paleontology, 30, 1451-1465.

Andrews, C. W. 1913. A Descriptive Catalogue of the Marine Reptiles of the Oxford Clay. Part Two. British Museum (Natural History), London, $206 \mathrm{pp}$

Barrientos-Lara, J. I., Herrera Y., Fernández, M. S. \& Alvarado-Ortega J. 2016. Occurrence of Torvoneustes (Crocodylomorpha, Metriorhynchidae) in marine Jurassic deposits of Oaxaca, Mexico. Revista Brasileira de Paleontologia, 19, 415-424.

Bell, M. A. \& Lloyd, G. T. 2015. strap: an R package for plotting phylogenies against stratigraphy and assessing their stratigraphic congruence. Palaeontology, 58, 379-389.

Benton, M. J. \& Spencer, P. S. 1995. Fossil reptiles of Great Britain. London: Chapman and Hall, London, 386 pp.

Brusatte, S. L., Muir, A., Young, M. T., Walsh, S., Steel, L. \& Witmer, L. M. 2016. The braincase and neurosensory anatomy of an Early Jurassic marine crocodylomorph: Implications for crocodylian sinus evolution and sensory transitions. The Anatomical Record, 299, 1511-1530.

Cau, A. 2013. The affinities of 'Steneosaurus barettoni' (Crocodylomorpha,Thalattosuchia), from the Jurassic of Northern Italy, and implications for cranial evolution among geosaurine metriorhynchids. Historical Biology, 26, 433-440.

Cau, A. \& Fanti, F. 2011. The oldest known metriorhynchid crocodilian from the Middle Jurassic of North-eastern Italy: Neptunidraco ammoniticus gen. et sp. nov. Gondwana Research, 19, 550-565.

Chiarenza, A. A., Foffa, D., Young, M. T., Insacco, G., Cau, A. Carnevale, G. \& Catanzariti, R. 2015. The youngest record of metriorhynchid crocodylomorphs, with 
implications for the extinction of Thalattosuchia. Cretaceous Research, 56, 608-616.

Cuvier, G. 1824. Article IV. Des os de deux espèces inconnues de Gavials; trouvés pêle-mêle près de Honfleur et du Hâvre. Sur les Ossemens Fossiles.Nouvelle édition, Tome Cinquieme, Partie 2. Dufour \& d'Occagne, Paris, pp. 143-160.

Eudes-Deslongchamps, E. 1867-1869. Notes paléontologiques. Le Blanc Hardel et Savy, Caen and Paris, pp. 320-392.

Fernández, M. S., Carabajal, A. P., Gasparini, Z. \& Chong Díaz, G. 2011. A metriorhynchid crocodyliform braincase from northern Chile. Journal of Vertebrate Paleontology, 31, 369-377.

Fitzinger, L. J. F. J. 1843. Systema reptilium. Braumüller et Seidel, Vienna, $136 \mathrm{pp}$.

Foffa, D. \& Young, M. T. 2014. The cranial osteology of Tyrannoneustes lythrodectikos (Crocodylomorpha: Metriorhynchidae) from the Middle Jurassic of Europe. PeerJ, 2, e608.

Foffa, D., Young, M. T. \& Brusatte, S. L. 2015. Evidence of macrophagous teleosaurid crocodylomorphs in the Corallian Group (Oxfordian, Late Jurassic) of the UK. PeerJ, 3, e1497.

Fraas, E. 1901. Die Meerkrokodile (Thalattosuchia n. g.) eine neue Sauriergruppe der Juraformation. Jahreshefte des Vereins für vaterländische Naturkunde in Württemberg, 57, 409-418.

Fraas, E. 1902. Die Meer-Krocodilier (Thalattosuchia) des oberen Jura unter specieller Berucksichtigung von Dacosaurus und Geosaurus. Palaeontographica, 49, 1-72.

Goloboff, P. A., Farris, J. S. \& Nixon, K. C. 2008. TNT, a free program for phylogenetic analysis. Cladistics, 24, 1-13.

Hay, O. P. 1930. Second Bibliography and Catalogue of the Fossil Vertebrata of North America 2. Carnegie Institute Washington, Washington DC, $1074 \mathrm{pp}$.

Hendry, J. P., Pearson, M. J., Trewin, N. H. \& Fallick, A. E. 2006, Jurassic septarian concretions from NW Scotland record interdependent bacterial, physical and chemical processes of marine mudrock diagenesis. Sedimentology, 53, $537-565$.

Herrera, Y., Gasparini, Z. \& Fernández, M.S. 2013. A new Patagonian species of Cricosaurus (Crocodyliformes, Thalattosuchia): first evidence of Cricosaurus in Middle-Upper Tithonian lithographic limestones from Gondwana. Palaeontology, 56, 663-678.

Herrera, Y., Gasparini, Z. \& Fernández, M. S. 2015. Purranisaurus potens Rusconi, an enigmatic metriorhynchid from the Late Jurassic-Early Cretaceous of the Neuquén Basin. Journal of Vertebrate Paleontology, e904790.

Jouve, S. 2009. The skull of Teleosaurus cadomensis (Crocodylomorpha; Thalattosuchia), and phylogenetic analysis of Thalattosuchia. Journal of Vertebrate Paleontology, 29, 88102.

Lepage, Y., Buffetaut, E., Hua, S., Martin, J. E. \& Tabouelle, J. 2008. Catalogue descriptif, anatomique, geologique et historique des fossiles presentes a l'exposition «Les crocodiliens fossiles de Normandie» (6 Novembre-14 Decembre 2008). Bulletin de la Société Géologique de Normandie et des Amis du Muséum du Havre, 95, 5-152.

Lydekker, R. 1888. Catalogue of the fossil Reptilia and Amphibia in the British Museum (Natural History). Part 1. British Museum (Natural History), London, 309 pp.

Lydekker, R. 1889. On the remains and affinities of five genera of Mesozoic reptiles. Quarterly Journal of the Geological Society, 45, 41-59.

Mannion, P. D., Benson, R. B. J., Carrano, M. T., Tennant, J. P., Ludd, J. \& Butler, R. J. 2015. Climate constrains the evolutionary history and biodiversity of crocodylians. Nature Communications, 6, 8438.
Montefeltro, F. C., Andrade, D. V. \& Larsson, H. C. E. 2016 The evolution of the meatal chamber in crocodyliforms. Journal of Anatomy, 228, 838-863. doi: 10.1111/joa.12439.

Parrilla-Bel, J., Young, M. T., Moreno-Azanza, J. \& Canudo, J. I. 2013. The first metriorhynchid crocodylomorph from the Middle Jurassic of Spain, with implications for evolution of the subclade Rhacheosaurini. PLoS ONE, 8, e54275.

Pol, D. \& Gasparini, Z. 2009. Skull anatomy of Dakosaurus andiniensis (Thalattosuchia: Crocodylomorpha) and the phylogenetic position of Thalattosuchia. Journal of Systematic Palaeontology, 7, 163-197.

Prasad, G. V. P. \& Broin, F. L. 2002. Late Cretaceous crocodile remains from Naskal (India): comparisons and biogeographic affinities. Annales de Paléontologie, 88, 19-71.

R Core Team 2013. $R$ : A language and environment for statistical computing. R Foundation for Statistical Computing, Vienna, Austria. URL http://www.R-project.org/.

Sellés-Martínez, J. 1996. Concretion morphology, classification and genesis. Earth-Science Reviews, 41, 177-210.

Walker, A. D. 1970. A revision of the Jurassic reptile Hallopus victor (Marsh), with remarks on the classification of crocodiles. Philosophical Transactions of the Royal Society of London, Series B, 257, 323-372.

Wilberg, E. W. 2015. A new metriorhynchoid (Crocodylomorpha, Thalattosuchia) from the Middle Jurassic of Oregon and the evolutionary timing of marine adaptations in thalattosuchian crocodylomorphs. Journal of Vertebrate Paleontology, e902846.

Wilkinson, L. E., Young, M. T. \& Benton, M. J. 2008. A new metriorhynchid crocodile (Mesoeucrocodylia: Thalattosuchia) from the Kimmeridgian (Upper Jurassic) of Wiltshire, UK. Palaeontology, 51, 1307-1333.

Young, M. T. 2014. Filling the 'Corallian Gap': re-description of a metriorhynchid crocodylomorph from the Oxfordian (Late Jurassic) of Headington, England, Historical Biology, 26, 80-90.

Young, M. T. \& Andrade, M. B. 2009. What is Geosaurus? Redescription of Geosaurus giganteus (Thalattosuchia: Metriorhynchidae) from the Upper Jurassic of Bayern, Germany. Zoological Journal of the Linnean Society, 157, 551-585.

Young, M. T., Brusatte, S. L., Ruta, M. \& Andrade, M. B. 2010. The evolution of Metriorhynchoidea (Mesoeucrocodylia, Thalattosuchia): an integrated approach using geometric morphometrics, analysis of disparity and biomechanics. Zoological Journal of the Linnean Society, 158, 801-859.

Young, M. T., Bell, M. A. \& Brusatte, M. B. 2011a. Craniofacial form and function in Metriorhynchidae (Crocodylomorpha: Thalattosuchia): modelling phenotypic evolution with maximum likelihood methods. Biology Letters, 7, 913-916.

Young, M. T., Brusatte, S. L. \& Andrade, M. B. 2011b. Body size estimation and evolution in metriorhynchid crocodylomorphs: implications for species diversification and niche partitioning. Zoological Journal of the Linnean Society, 163, $1199-1216$

Young, M. T., Brusatte, S. L., Andrade, M. B., Desojo, J. B., Beatty, B. L., Steel, L., Fernández, M. S., Sakamoto, M. Ruiz-Omeñaca, J. I. \& Schoch, R. R. 2012a. The cranial osteology and feeding ecology of the metriorhynchid crocodylomorph genera Dakosaurus and Plesiosuchus from the Late Jurassic of Europe. PLoS ONE, 7, e44985.

Young, M. T., Brusatte, S. L., Andrade, M. B., Beatty, L. \& Desojo, J. B. 2012b. Tooth-on-tooth interlocking occlusion suggests macrophagy in the Mesozoic marine crocodylomorph Dakosaurus. The Anatomical Record, 295, 1147-1158.

Young, M. T., Andrade, M. B., Etches, S. \& Beatty, B. L. 2013a. A new metriorhynchid crocodylomorph from the 
Lower Kimmeridge Clay Formation (Late Jurassic) of England, with implications for the evolution of dermatocranium ornamentation in Geosaurini. Zoological Journal of the Linnean Society, 169, 820-848.

Young, M. T., Andrade, M. B., Brusatte, S. L., Sakamoto, M. \& Liston, J. 2013b. The oldest known metriorhynchid super-predator: a new genus and species from the Middle Jurassic of England, with implications for serration and mandibular evolution in predacious clades. Journal of Systematic Palaeontology, 11, 475-513.

Young, M. T., Hua, S., Steel, L., Foffa, D., Brusatte, S. L., Thüring, S., Mateus, O., Ruiz-Omeñaca, J. I., Havlik, P., Lepage, Y. \& Andrade, M. B. 2014a. Revision of the Late Jurassic teleosaurid genus Machimosaurus (Crocodylomorpha, Thalattosuchia). Royal Society Open Science, 1, 140222.
Young, M. T., Steel, L., Brusatte, S. L., Foffa, D. \& Lepage, Y. 2014b. Tooth serration morphologies in the genus Machimosaurus (Crocodylomorpha, Thalattosuchia) from the Late Jurassic of Europe. Royal Society Open Science, 1, 140269.

Young, M. T., Steel, L. \& Middleton, H. 2014c. Evidence of the metriorhynchid crocodylomorph genus Geosaurus in the Lower Kimmeridge Clay Formation (Late Jurassic) of England. Historical Biology, 26, 551-555.

Young, M. T., Hastings, A. K., Allain, R. \& Smith, T. J. 2016. Revision of the enigmatic crocodyliform Elosuchus felixi de Lapparent de Broin, 2002 from the Lower-Upper Cretaceous boundary of Niger: potential evidence for an early origin of the clade Dyrosauridae. Zoological Journal of the Linnean Society, doi:10.1111/zoj.12452 